Article

\title{
Water Salinity as Potential Aid for Improving the Carbon Dioxide Replacement Process' Effectiveness in Natural Gas Hydrate Reservoirs
}

\author{
Alberto Maria Gambelli * ${ }^{\mathbb{D}}$, Beatrice Castellani $\mathbb{D}^{\mathbb{D}}$, Andrea Nicolini ${ }^{\mathbb{D}}$ and Federico Rossi ${ }^{\mathbb{D}}$ \\ Engineering Department, University of Perugia, Via G.Duranti 67, 06125 Perugia, Italy; \\ beatrice.castellani@unipg.it (B.C.); andrea.nicolini@unipg.it (A.N.); federico.rossi@unipg.it (F.R.) \\ * Correspondence: albertomaria.gambelli@unipg.it; Tel.: +39-0744-92985
}

Received: 3 September 2020; Accepted: 12 October 2020; Published: 16 October 2020

\begin{abstract}
Natural gas hydrates represent a valid opportunity to counteract two of the most serious issues that are affecting humanity this century: climate change and the need for new energy sources, due to the fast and constant increase in the population worldwide. The energy that might be produced with methane contained in hydrates is greater than any amount of energy producible with known conventional energy sources; being widespread in all oceans, they would greatly reduce problems and conflicts associated with the monopoly of energy sources. The possibility of extracting methane and simultaneously performing the permanent storage of carbon dioxide makes hydrate an almost carbon-neutral energy source. The main topic of scientific research is to improve the recovery of technologies and guest species replacement strategies in order to make the use of gas hydrates economically advantageous. In the present paper, an experimental study on how salt can alter the formation process of both methane and carbon dioxide hydrate was carried out. The pressure-temperature conditions existing between the two respective equilibrium curves are directly proportional to the effectiveness of the replacement process and thus its feasibility. Eighteen formation tests were realized at three different salinity values: 0,30 and $37 \mathrm{~g} / \mathrm{L}$. Results show that, as the salinity degree increases, the space between $\mathrm{CO}_{2}$ and $\mathrm{CH}_{4}$ formation curves grows. A further aspect highlighted by the tests is how the carbon dioxide formation process tends to assume a very similar trend in all experiments, while curves obtained during methane tests show a similar trend but with some significant differences. Moreover, this tendency became more pronounced with the increase in the salinity degree.
\end{abstract}

Keywords: gas hydrate; methane; $\mathrm{CO}_{2}$ replacement; production and reservoirs

\section{Introduction}

Gas hydrates are solid crystalline compounds formed under favorable thermodynamic conditions from mixtures of water molecules (also called hosts) and small molecules of gaseous compounds (guests), such as methane $\left(\mathrm{CH}_{4}\right)$, hydrogen $\left(\mathrm{H}_{2}\right)$, nitrogen $\left(\mathrm{N}_{2}\right)$, helium $(\mathrm{He})$ and carbon dioxide $\left(\mathrm{CO}_{2}\right)$. In hydrate structures, the gas molecules are entrapped inside cage-like cavities composed by hydrogen-bonded water molecules [1]. The stability and chemical characteristics of natural gas hydrate (NGH) have been investigated since the 1930s [2-4]. Three main structures were identified: structural I (sI) and structural II (sII), which are cubic, and structure H (sH), which is hexagonal [5]. The structure form is mainly affected by the gas guest molecules and thermodynamic conditions [6]. Natural gas hydrate mainly originates from two different aspects: thermogenic and biogenic $[7,8]$. The first originates from the decomposition of organics, which causes the production of methane and other hydrocarbons, such as ethane $\left(\mathrm{C}_{2} \mathrm{H}_{6}\right)$ and propane $\left(\mathrm{C}_{3} \mathrm{H}_{8}\right)$ [9]; the second is instead generated from methanogens [10]. NGH reservoirs have been discovered in marine sediments and 
in permafrost regions [11]. The most important marine deposits were found in the Gulf of Mexico, Indian Ocean, South China, Japan, Korea and Bearing Strait [12]. On the other side, the greatest permafrost areas dominated by hydrate presence are Alaska, Siberia, Qinghai-Tibet and the Mackenzie Delta [13]. At least 99\% of discovered NGH reservoirs have been found in marine continental margins, mostly at depths greater than $1000 \mathrm{~m}$ [14]. Boswell and Collett (2011) affirmed that, nowadays, approximately $3 \times 10^{15} \mathrm{~m}^{3}$ of methane is entrapped in water cages and forms NGH deposits [15]. Sediments containing natural gas hydrate can be divided into three different types in terms of their morphology: pore filling, naturally fractured and massive/noddle [16]. Since their discovery, NGH have been considered a potential energy source for contrasting critical problems, such as the growing energy demand and climate change [17,18]. Several uses were investigated and performed: their structures may be used for gas storage [19,20], gas transportation [21], refrigeration [22], gas mixture separation [23], marine water desalination [24] and others. In the past few decades, several strategies for exploiting hydrate deposits were developed [25] and the most common of them are briefly described below. The depressurization strategy consists in lowering the deposit pressure below the hydrate equilibrium value at the local temperature, without varying this last parameter [26,27]. With thermal stimulation, the same method is carried out, but by modifying the temperature and keeping the pressure constant $[28,29]$. Chemical inhibitor injection is a strategy based on moving the NGH equilibrium curve to higher pressure and lower temperature, leaving the hydrate unstable at the local thermodynamic conditions [30,31]. Finally, the $\mathrm{CO}_{2}-\mathrm{CH}_{4}$ replacement method enables methane recovery through two contemporary actions. Firstly, a little variation in the deposit conditions is provided, in order to generate instability for NGH at the local conditions. Then, carbon dioxide is injected into the reservoir, due to its ability to form hydrate even at a higher temperature and/or lower pressure than methane [32,33]. Moreover, this solution leads to permanent storage of carbon dioxide and permits the generation of a carbon neutral energy source [34]. In the present experimental work, we investigated the $\mathrm{CO}_{2}-\mathrm{CH}_{4}$ replacement process in the presence of a natural chemical inhibitor: sodium chloride $(\mathrm{NaCl})$. The hydrate formation is indeed hindered in the presence of electrolytes dissolved in liquid water [35]. Experimental data, models and simulation of hydrate formation and dissociation in the presence of electrolytes are widely shown in the literature [36-43]. All these works prove how the presence of salt dissolved in water causes an increase in hydrate equilibrium pressure and/or a decrease in their equilibrium temperature [44]. The inhibitor effect is due to the competition between ions and guest molecules, which leads to a decrease in hydrogen bonds between water molecules [45]. Thus, the formation of water cages is hindered, and clathrate structure stability is also reduced [46]. Thanks to their experiments on the inhibiting effect of different electrolyte solutions for hydrate formation, Lu et al. (2001) [46] were also able to prove that the main factors responsible for variations in hydrate equilibrium thermodynamic conditions, in the presence of an electrolyte solution, are anions. A possible explanation of such behavior was provided by Makogon Y.F. (1981), who highlighted differences between salts in acting as chemical inhibitors with the salting-out effect. As explained in [46], with the "salting-out effect", the reduction of a certain salt's solubility due to the addition of a kind of salt is indicated. Moreover, sodium chloride permits us to avoid the major problems related to using chemical inhibitors: diffusion and effective permeability to solution in the reservoir, costs and environment preservation. The feasibility of the carbon dioxide replacement process remains in the distance existing between the pressure-temperature curves of $\mathrm{CO}_{2}$ and $\mathrm{CH}_{4}$ hydrate formation [47]. Figure 1 shows a comparison between pressure-temperature data measured over time during a methane hydrate and a carbon dioxide hydrate formation process. 


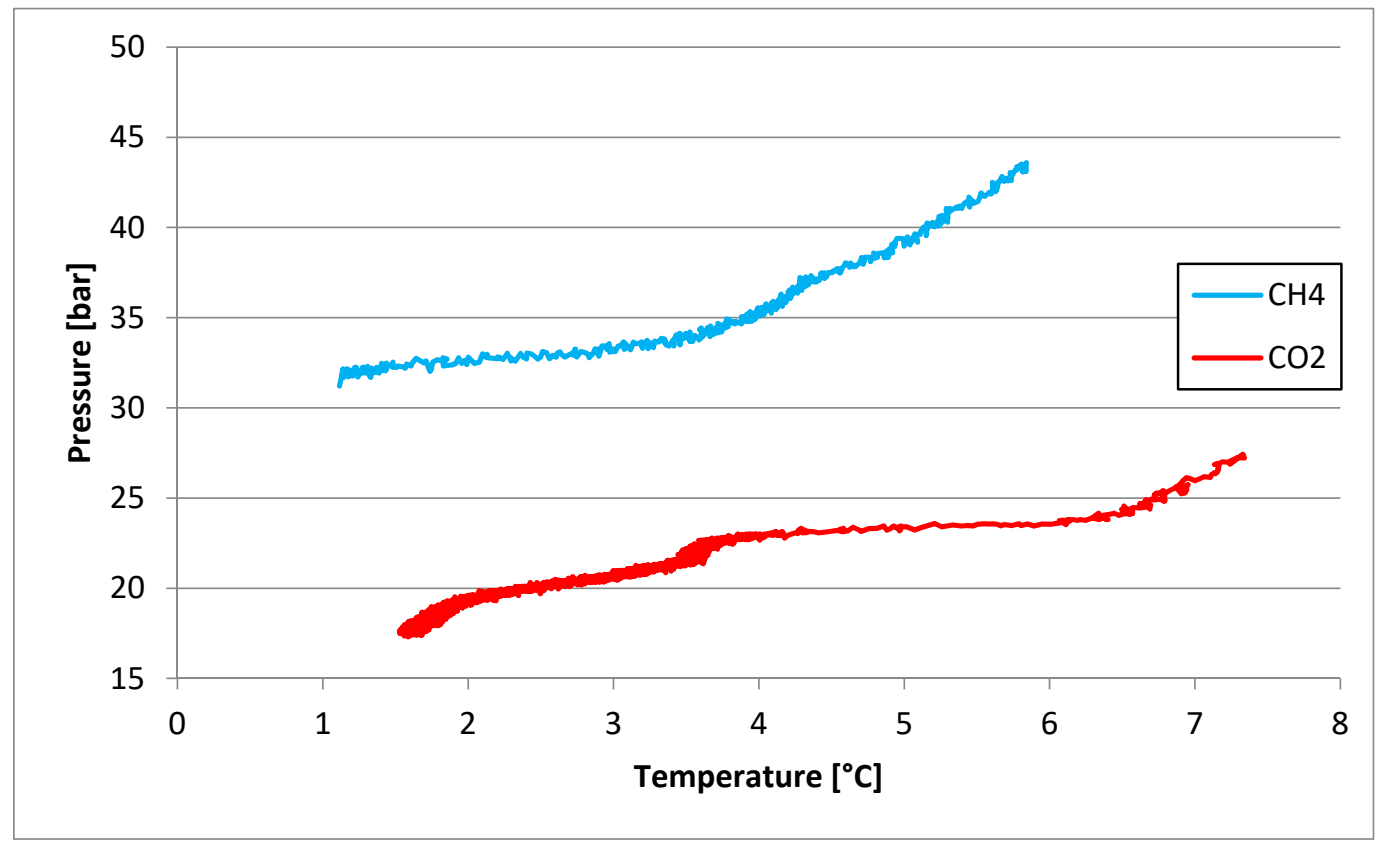

Figure 1. Comparison between P-T diagrams of hydrate formation carried out with methane (in blue) and carbon dioxide (in red).

Numeric results related to this diagram are shown in Gambelli and Rossi (2019) [48] and were obtained using the same experimental apparatus adopted for the present work, which will be briefly described in Section 2. In Figure 1, the region between methane (red color) and carbon dioxide (blue color) curves represents the set of all pressure-temperature values which make the $\mathrm{CO}_{2}-\mathrm{CH}_{4}$ replacement process feasible. The experimental section of this work is involved in investigating if the dimensions of this thermodynamic area may change in the presence of salt water. An increase in the pressure and temperature range feasible for the replacement could make this process easier and could increase its efficiency. The possibility of using a classical inhibitor compound for the hydrate formation process, as a promoter of the replacement of methane contained in hydrates with carbon dioxide, was also supported by several experimental results already present in the literature. $\mathrm{Ng}$ and Robinson [49] proved that acetone is a promoter for methane hydrate formation. However, the usage of excessive quantities of it ( $>0.06$ mole fraction) leads to hydrate formation inhibition. If acetone is able to act as a promoter for methane hydrate formation, Javanmardi et al. [50] proved that, in the case of R22 hydrate formation, acetone has only an inhibiting effect. Finally, a clear motivation of the necessity to experimentally verify differences in inhibitors behavior is provided in Maekawa [51]: "Thus the inhibiting or promoting effect of acetone on clathrate hydrate formation depends on its concentration in solution and the type of guest gas molecule". In Yokoi S. et al. (1993) [52], it was proven that some cyclic ethers, such as tetrahydrofuran, 1,4-dioxane and 1,3-dioxilane, are able to promote $\mathrm{CH}_{4}$ hydrate formation in a manner similar to acetone. Jager et al. (1999) [53] evaluated methane hydrate formation in the presence of several concentrations of 1,4-dioxane and concluded that, at concentrations higher than 0.06 mole fraction, this compound is able to reduce the methane hydrate equilibrium pressure. Moreover, 1,4-dioxane and 1,3-dioxolane may also act as promoters for carbon dioxide hydrate formation; however, these compounds are chemical inhibitors of ethane hydrate formation [51]. A further example is provided by Maekawa T. (2011) [54], where acetone was found to be a chemical inhibitor of propane until concentrations were lower than 0.16 mass fraction. Methylcyclohexane is a good methane hydrate promoter but, at the same time, is an inhibitor of hydrate formation of $\mathrm{CH}_{4} / \mathrm{C}_{2} \mathrm{H}_{6} / \mathrm{C}_{3} \mathrm{H}_{8}$ mixtures [55]. Maekawa T. (2008) [56] defined the equilibrium conditions of $\mathrm{CH}_{4}$ hydrate in water containing 2-propanol. Results produced were useful to confirm the thermodynamic model introduced in Ostergaard K.K. et al. (2002) [57], where 2-propanol was suggested as an additive 
able to act as an sII former for methane hydrate. Then, Ohmura R. et al. (2004) [58] carried out methane hydrate formation tests with a $16.4 \%$ mass aqueous solution of 2-propanol and then used the X-ray diffraction analysis to confirm the formation of sII hydrate containing both methane and 2-propanol. Thus, a classical chemical inhibitor may act as a promoter for a specific compound. Pahlavanzadeh H. and colleagues (2019) [59] proved the ability of 1,3,5-trioxane and 2,5-dihydrofuran to act as good chemical promoters, especially if coupled. However, 2-methyl-2-propanol acts as an effective chemical inhibitor in the presence of carbon dioxide. All these examples prove how several different chemical compounds were tested on a single-species hydrate or in the case of gaseous mixtures, in order to prove variations in their inhibiting/promoting characteristics in the presence of the guest species and in relation to their concentration. However, in this direction, the presence in the literature of experimental data about sodium chloride needs to be improved and deepened. In this direction, some researchers produced encouraging data about the contemporary use of salts and chemical promoters such as Tetra-butylammonium-bromide (TBAB.) Sangway J.S. and Oellrich L. (2014) [60] tested semiclathrate hydrate of methane and $\mathrm{TBAB}$ in the presence of $\mathrm{NaCl}$ in aqueous solution. They concluded that for $\mathrm{w}_{\mathrm{NaCl}}$ equal to both 0.03 and $0.1, \mathrm{NaCl}$ well inhibited methane hydrate in the presence of 0.2 mass fraction of TBAB; conversely, a promoting effect was achieved for $\mathrm{w}_{\mathrm{NaCl}}=0.03$ in $\mathrm{w}_{\mathrm{TBAB}}=0.05$. A greater thermodynamic area between methane and carbon dioxide equilibrium curves means having the possibility to create local conditions more unfeasible for methane hydrate formation and stability than classical situations, while remaining in a region of stability and formation of carbon dioxide hydrate. Moreover, the possibility of increasing the spacing from methane hydrate equilibrium leads to the acceleration of its dissociation. Several authors assert that one of the most limiting factors of $\mathrm{CO}_{2}$ replacement in natural gas reservoirs is that the process occurs only in the most superficial layers, because $\mathrm{CO}_{2}$ hydrate formation in this area prevents gas flowing in the reservoir core before methane dissociation occurs (in correspondence with these internal layers). Thus, greater spacing between the two respective equilibrium curves may also help to extend the replacement area to more in-depth layers and so increase the overall process' effectiveness.

Starting from this consideration, in this paper, sodium chloride's characteristics as a chemical inhibitor in the presence of a single-species hydrate have been tested, while the evaluation of its behavior during a complete $\mathrm{CO}_{2} / \mathrm{CH}_{4}$ replacement process has been postponed to future works. Moreover, the water salinity of hydrate marine reservoirs changes in relation to their geographic position [61] and the greatest percentage of them is located in sites characterized by water salinity in the range of 30-37 g/L. Thus, in the experimental section of the present work, methane hydrate and carbon dioxide hydrate formation were tested with three different salt concentration values in water: $0 \mathrm{~g} / \mathrm{L}$ or, in the absence of salt, 30 and $37 \mathrm{~g} / \mathrm{L}$.

For each salinity degree, a comparison between methane and carbon dioxide equilibrium curves was carried out in order to locate and consequently analyze any differences.

\section{Materials and Methods}

\subsection{Experimental Apparatus}

The lab-scale reactor adopted for the following experimental section has already been used for other different types of experiments and a detailed description is available elsewhere in the literature $[25,34,47]$. However, in this paragraph, its main characteristics are briefly summarized. The whole reactor was realized with 316SS stainless steel and has an internal cylindrical volume of $949 \mathrm{~cm}^{3}$; in particular, the diameter is equal to $7.3 \mathrm{~cm}$ while the internal height is around $22.1 \mathrm{~cm}$. Both the upper and the lower surface of this volume are sealed with two 316SS stainless steel flanges (both of them composed by two $4.7 \mathrm{~cm}$ thick plates).

The whole reactor is shown in Figure 2. 


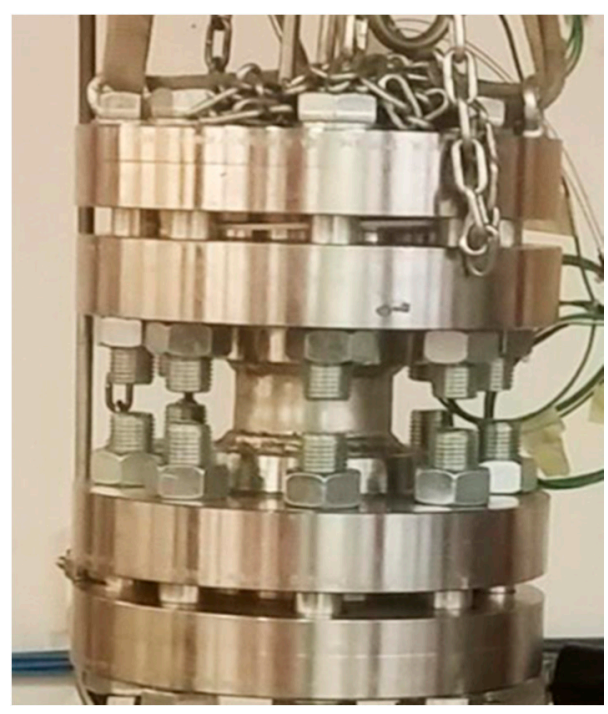

Figure 2. Image of the lab-scale apparatus used for hydrate formation tests.

The methane injection pipe passes through the lower flange, while the carbon dioxide one is inserted in the upper flange. While methane directly flows from the lower flange, carbon dioxide passes through an internal pipe which leads it toward the methane injection area. The presence of such a pipe has been clearly considered in the internal free volume evaluation. Here, another four channels are presented for the insertion of four Type $\mathrm{K}$ thermocouples, having class accuracy 1 and a digital manometer (Model MAN-SD, with accuracy equal to $\pm 0.5 \%$ of full scale) inside the internal volume. Thermocouples are located at different depths, in order to precisely monitor temperature and well identify differences due to hydrate formation or dissociation. All devices are connected with a data acquisition system manufactured by National Instruments for monitoring and recording experimental data, which is operated with Labview software. Figure 3 shows a schematization of the completely assembled experimental apparatus. In this figure, each thermocouple position is indicated with a black dot situated on a vertical line defined with letter " $\mathrm{T}$ ".

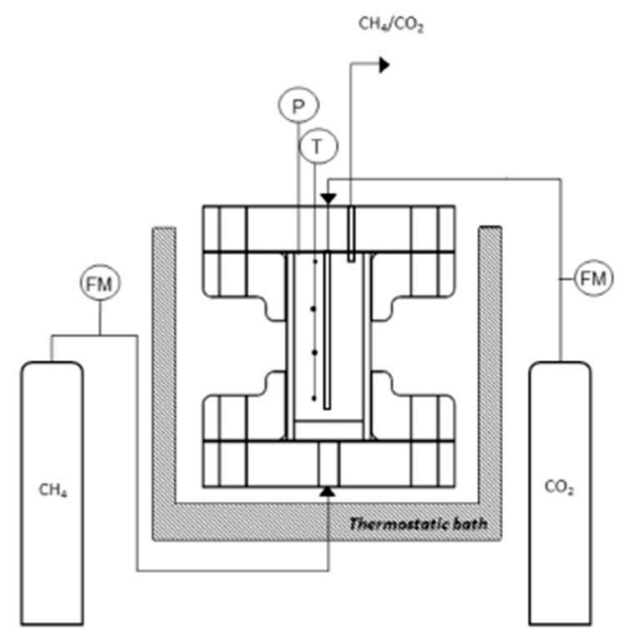

Figure 3. Schematization of the completely assembled experimental apparatus.

In the present figure, thermocouples and the manometer are indicated respectively with letter " $\mathrm{T}$ " and " $\mathrm{P}$ "; fluximeters are described with "FM" and are situated between the reactor and both cylinders, for constantly monitoring the gas quantities injected inside the reactor. Finally, the whole reactor is inserted inside a thermostatic bath, used for regulating its internal temperature. This vessel is filled with water and glycol and is refrigerated by a chiller, model GC-LT (by Euro-Chiller). 


\subsection{Materials}

The internal volume was filled with silica quartz sand and pure demineralized water (which was already present inside the reactor before the beginning of each experiment). Sand was composed of quartz spheres having an average of $500 \mu \mathrm{m}$ diameter and a porosity equal to $34 \%$ (measured with a porosimeter, model Thermo Scientific Pascal). The reactor internal volume was filled with $0.744 \mathrm{~L}$ of sand and $0.236 \mathrm{~L}$ of water. The free space useful for gas injection is given by the difference between the total volume $(0.949 \mathrm{~L})$ and these two values. Regarding sand volume, it has to be multiplied for 0.66 , because its pores generate free space for gas injection and subsequent hydrate formation. Gases used for this experimental experience were methane $\left(\mathrm{CH}_{4}\right)$ and carbon dioxide $\left(\mathrm{CO}_{2}\right)$, both provided by Air Liquide and characterised by ultra-high purity grade (UHP), with a purity degree respectively of $99.97 \%$ for methane and $99.99 \%$ for carbon dioxide. As far as experiments carried out in the presence of an inhibitor, pure sodium chloride $(\mathrm{NaCl})$ was used.

\subsection{Experimental Procedure}

Firstly, the reactor was kept under vacuum. Then, methane was introduced at a pressure value fractionally higher than the atmospheric pressure (at least 1.1-1.2 bar), for at least $15 \mathrm{~min}$, in order to completely remove any air infiltration inside the reactor, during the opening of connections. Then, pressure was increased till reaching the desired value and the hydrate formation process begun. Tests consisted only of the formation phase because of the necessity of comparing equilibrium pressure-temperature values between tests realized with $\mathrm{CH}_{4}$ and tests with $\mathrm{CO}_{2}$. The process performed for studying the hydrate phase boundary was carried out at isochoric conditions, while heat addition or removal was guaranteed from the external. Gas injection started once the internal temperature reached $2-3{ }^{\circ} \mathrm{C}$ and stabilized around this value. Then, pressure was increased, maintaining a constant temperature as much as possible, until reaching the desired value. As soon as $\mathrm{P}-\mathrm{T}$ conditions reached values feasible for hydrate formation, the process began. In the following section, the gas injection phase will not be described and diagrams will show only the hydrate formation process. In order to verify if the hydrate formation reaction involved the whole reactor's internal volume, during all experiments, temperature was measured at four different depths, to determine hydrate formation thanks to the exothermal reaction. Sensors used for temperature measurements consisted of Type K thermocouples, with class accuracy 1 , and were positioned respectively at 2, 7,11 and $16 \mathrm{~cm}$ from the upper section of the reactor. This procedure confirmed massive hydrate formation inside the porous medium. In particular, thermocouples also permitted us to verify that, in all tests conducted, the initial and the final temperature values were equal (a negligible difference among these values was observed), while during formation, mostly when the reaction started, the heat production related to hydrate formation led to a temporary temperature increase. In the next section, tests conducted are described via their pressure-temperature relation, so this aspect will be not further highlighted. In the absence of sand, hydrate formation and, in particular, the heterogeneous nucleation phase, would occur near the reactor walls, due to the presence of small impurities which act as promoters for the process [62]. Here, the gas injection from the lowest area of the internal volume and the contemporary presence of a porous medium led to the formation of several gas-liquid interfaces near solid elements that guaranteed hydrate formation in all the reactor's volume occupied by the porous medium.

For each test, some useful parameters were measured and others were calculated. Pressure and temperature were measured at the beginning and at the end of all tests. Moles of gas injected inside the reactor were measured with fluximeters and were also calculated. Thus, considering the internal volume useful for hosting gas, temperature, pressure and calculating the compressibility factor with the Peng-Robinson equation, the precise quantity of gaseous moles injected inside the reactor was evaluated. Moles of formed hydrate were calculated considering the difference between the initial and the final pressure value. Finally, the tendency of guest molecules to be trapped in crystalline water cavities was evaluating by defining parameter " $\eta$ ", which consists in the ration between the theoretical pressure values that, in ideal conditions, should be registered at the end of each test, and the 
real pressure, effectively measured at the end of each experiment. The theoretical one was evaluated using CSM.HYD software. Obviously, the introduction of sodium chloride in aqueous solution led to a decrease in quantities of hydrate formed, thus determining a reduction of such parameters. This parameter allowed us to verify how $\mathrm{NaCl}$ affected the formation process and for which species its inhibiting activity was stronger; for this reason, it was considered a measure of the process efficiency.

\section{Results and Discussion}

The experimental section consists of 18 hydrate formation tests, carried out at three different salt concentrations: 0,30 and $37 \mathrm{~g} / \mathrm{L}$. For each salinity degree, six tests were conducted, divided in equal parts between tests realized with methane and tests realized with carbon dioxide. Several parameters may intervene in the hydrate formation process, thus leading to varied final results (i.e., porous medium permeability, gas diffusion inside the medium and presence of impurities). Moreover, the formation process is stochastic. In order to reduce as much as possible uncertainties related to these arguments, each kind of test was repeated three times. For each test, a table containing all parameters of interest is shown. Each diagram, which will be shown below, compares two different tests, realized with the same salinity degree but using different gaseous compounds.

\subsection{Tests Carried Out in Pure Demineralized Water}

Tables 1-3 and Figures 4-6 described in this section and in the following are related to two tests, differing from each other for the gaseous species involved in the experiment. In this way, a comparison of common aspects and differences was possible.

Table 1. Parameters related to Test 1 (with $\mathrm{CH}_{4}$ ) and Test 4 (with $\mathrm{CO}_{2}$ ).

\begin{tabular}{cccc}
\hline Parameters & Test $\mathbf{1}$ & Test $\mathbf{4}$ & Measure Units \\
\hline $\mathrm{Pi}$ & 44.21 & 25.82 & $\mathrm{bar}$ \\
$\mathrm{Ti}$ & 5.84 & 5.99 & ${ }^{\circ} \mathrm{C}$ \\
$\mathrm{Pf}$ & 31.22 & 17.09 & $\mathrm{bar}$ \\
$\mathrm{Tf}$ & 1.12 & 2.86 & ${ }^{\circ} \mathrm{C}$ \\
$\mathrm{Zi}$ & 0.87 & 0.83 & - \\
$\mathrm{Zf}$ & 0.90 & 0.89 & - \\
$\mathrm{mol}_{\mathrm{INJ}}$ & 0.556 & 0.435 & $\mathrm{~mol}$ \\
$\mathrm{~mol}_{\mathrm{HYD}}$ & 0.189 & 0.122 & $\mathrm{~mol}$ \\
$\mathrm{~mol}_{\text {DISS }}$ & - & 0.004 & $\mathrm{~mol}$ \\
$\eta$ & 0.915 & 0.909 & - \\
\hline
\end{tabular}

Table 2. Parameters related to Test 2 (with $\mathrm{CH}_{4}$ ) and Test 5 (with $\mathrm{CO}_{2}$ ).

\begin{tabular}{cccc}
\hline Parameters & Test 2 & Test 5 & Measure Units \\
\hline $\mathrm{Pi}$ & 48.44 & 27.43 & $\mathrm{bar}$ \\
$\mathrm{Ti}$ & 5.51 & 6.96 & ${ }^{\circ} \mathrm{C}$ \\
$\mathrm{Pf}$ & 34.94 & 17.71 & $\mathrm{bar}$ \\
$\mathrm{Tf}$ & 0.20 & 2.39 & ${ }^{\circ} \mathrm{C}$ \\
$\mathrm{Zi}$ & 0.86 & 0.83 & - \\
$\mathrm{Zf}$ & 0.89 & 0.89 & - \\
$\mathrm{mol}_{\text {INJ }}$ & 0.618 & 0.359 & $\mathrm{~mol}$ \\
$\mathrm{~mol}_{\text {HYD }}$ & 0.204 & 0.136 & $\mathrm{~mol}$ \\
$\mathrm{~mol}_{\text {DISS }}$ & - & 0.004 & $\mathrm{~mol}$ \\
$\eta$ & 0.987 & 0.878 & - \\
\hline
\end{tabular}


Table 3. Parameters related to Test 3 (with $\mathrm{CH}_{4}$ ) and Test 6 (with $\mathrm{CO}_{2}$ ).

\begin{tabular}{cccc}
\hline Parameters & Test $\mathbf{3}$ & Test $\mathbf{6}$ & Measure Units \\
\hline $\mathrm{Pi}$ & 48.06 & 26.88 & $\mathrm{bar}$ \\
$\mathrm{Ti}$ & 4.84 & 7.24 & ${ }^{\circ} \mathrm{C}$ \\
$\mathrm{Pf}$ & 28.86 & 17.62 & $\mathrm{bar}$ \\
$\mathrm{Tf}$ & 1.58 & 1.62 & ${ }^{\circ} \mathrm{C}$ \\
$\mathrm{Zi}$ & 0.86 & 0.83 & - \\
$\mathrm{Zf}$ & 0.91 & 0.89 & - \\
$\mathrm{mol}_{\text {INJ }}$ & 0.615 & 0.35 & $\mathrm{~mol}$ \\
$\mathrm{~mol}_{\mathrm{HYD}}$ & 0.275 & 0.129 & $\mathrm{~mol}$ \\
$\mathrm{~mol}_{\mathrm{DISS}}$ & - & 0.004 & $\mathrm{~mol}$ \\
$\eta$ & 0.989 & 0.789 & - \\
\hline
\end{tabular}

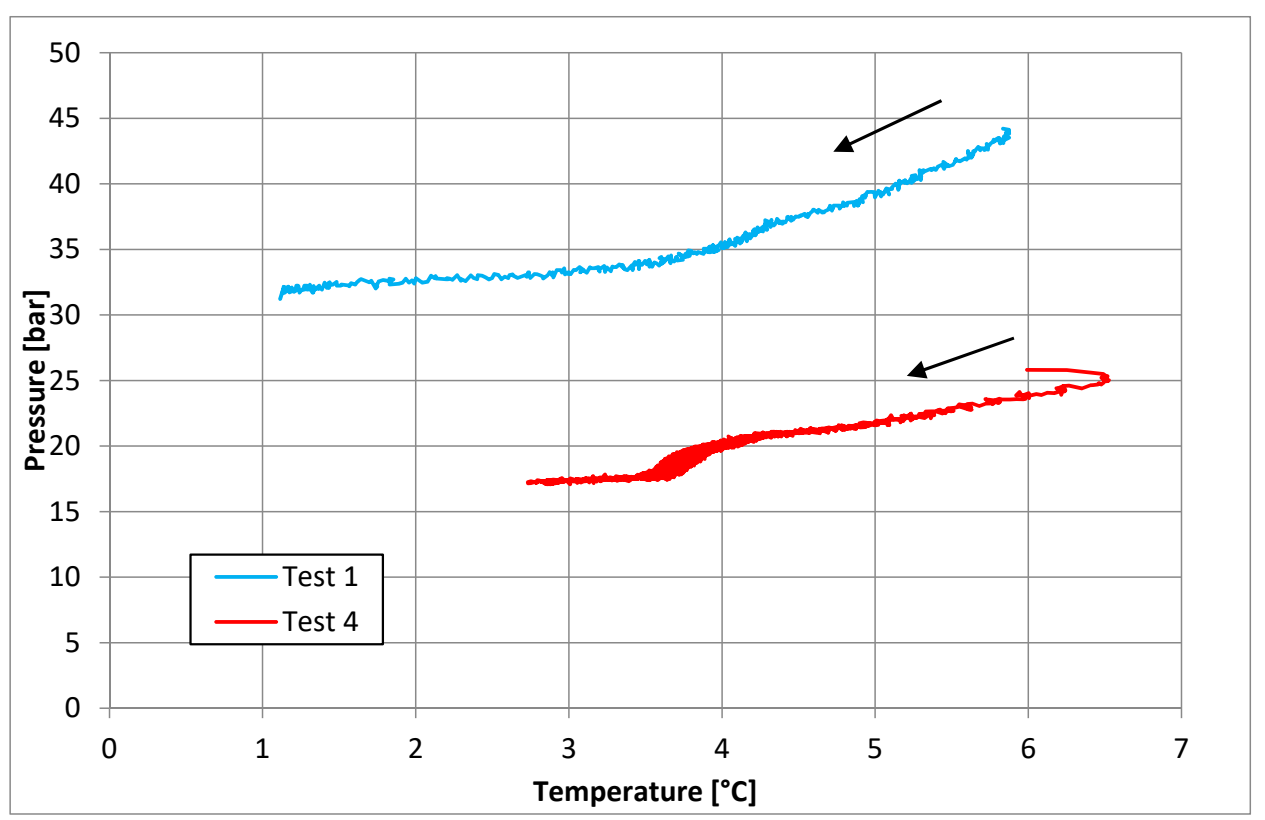

Figure 4. Comparison between Test 1 , carried out using $\mathrm{CH}_{4}$, and Test 4, performed with $\mathrm{CO}_{2}$.

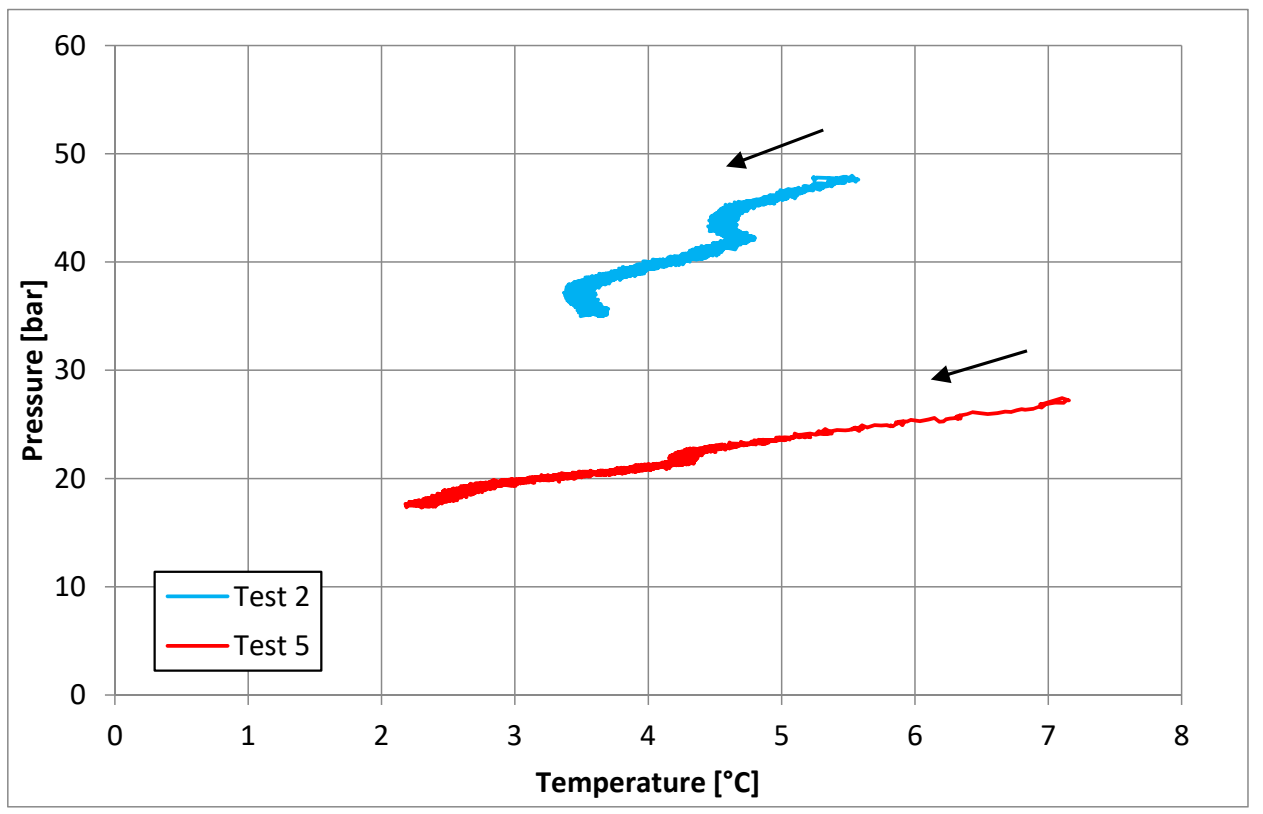

Figure 5. Comparison between Test 2, carried out using $\mathrm{CH}_{4}$, and Test 5, performed with $\mathrm{CO}_{2}$. 


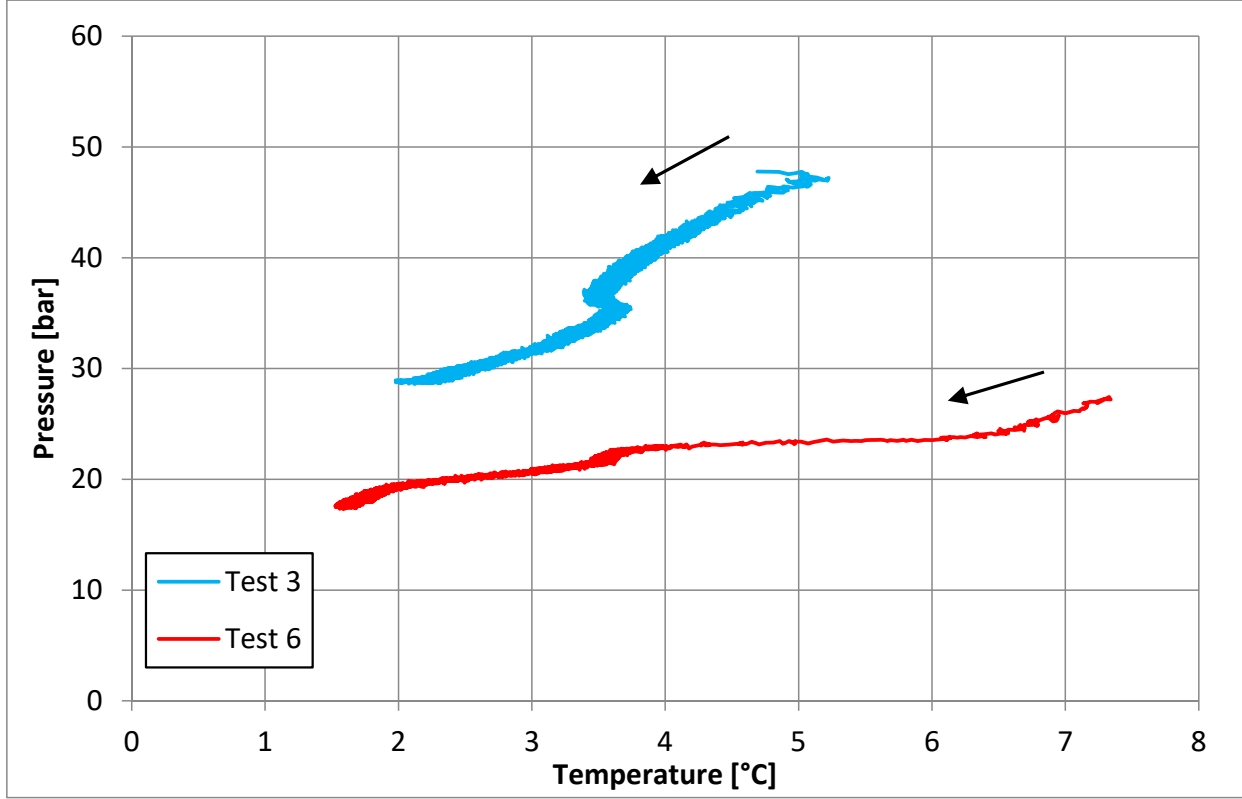

Figure 6. Comparison between Test 3, carried out using $\mathrm{CH}_{4}$, and Test 6, performed with $\mathrm{CO}_{2}$.

Figures 4-6 show the relation existing between pressure and temperature during hydrate formation; the blue color was used for methane, while the red color was used for carbon dioxide. A black arrow indicates the time direction: each diagram describes pressure and temperature reduction during hydrate formation. While the pressure value is reached artificially by injecting gas inside the reactor, the initial temperature value is due to the heat production related to the reaction triggering. The following decrease in temperature is caused by the whole system, which tends to restore its previous thermal equilibrium. In all experiments, pressure continued to decrease until it reached a constant value, namely by the end of the hydrate formation process. Since the focus of these diagrams is the formation phase, the initial stage where pressure increased and reaction occurred and the final stage where a stable signal was reached are not shown. The hydrate formation process is stochastic and depends on several factors, such as reactor dimensions and its geometry, initial pressure, sand pores saturation degree and so on [63]. These reasons explain why the initial and final temperature of tests did not coincide. Another interesting aspect underlined by the diagrams is the more disordered behavior registered during methane hydrate formation. This aspect will be confirmed also in other sections (describing tests carried out in the presence of sodium chloride). Carbon dioxide hydrate formation appeared as a more ordered process, with a higher repeatability degree. This aspect may have more than one explanation. Surely, the higher $\mathrm{CO}_{2}$ dissolution in water rate contributed to more homogeneous gas diffusion around and inside sand pores. Moreover, $\mathrm{CO}_{2}$ hydrate formation started at a significantly lower pressure value than the $\mathrm{CH}_{4}$ one: this means a lower sand pores saturation degree. In previous works, such as Rossi et al. (2019) [25], authors illustrated how the increase in the saturation degree is associated with higher differences between the ideal formation process and the real behavior. In Gambelli et al. (2019) [64], the authors also proved how a higher saturation degree reduces the percentage of gas entrapped in hydrate structures. In this case, measurements were made during the $\mathrm{CO}_{2} / \mathrm{CH}_{4}$ replacement process and concerned the carbon dioxide capability of both replacing methane into already existing ice cavities and forming new hydrate. This aspect was not found in the present work, just because tests realized with the same gaseous species were carried out with a very similar saturation degree and, moreover, the tests concerned only new hydrate formation; thus, the ratio between gas involved in hydrate and gas injected inside the reactor cannot be compared. However, this hydrate formation characteristic clearly appears in the hydrate formation behavior, which is significantly more repeatable if carbon dioxide is used rather than methane. In this work, the ratio between theoretical end-test pressure (evaluated with the CSM.HYD software) and the 
experimental value was identified with the Greek letter " $\eta$ " and describes the process efficiency. As far as carbon dioxide is concerned, moles dissolved in water were not taken into account in parameter " $n_{\mathrm{HYD}}$ " but were considered in " $\mathrm{n}_{\mathrm{INJ}}$ " (while methane dissolution in water is in each case negligible). There are no significant differences between efficiency values reached in methane or in carbon dioxide formation tests: in each case, $\eta$ is in the range $0.878-0.989$.

\subsection{Tests Carried Out in Presence of Salt, with a Concentration of $30 \mathrm{~g} / \mathrm{L}$}

As in the previous section, tests are divided into three Figures 7-9, and three Tables 4-6 for a clearer comparison between methane and carbon dioxide formation experiments.

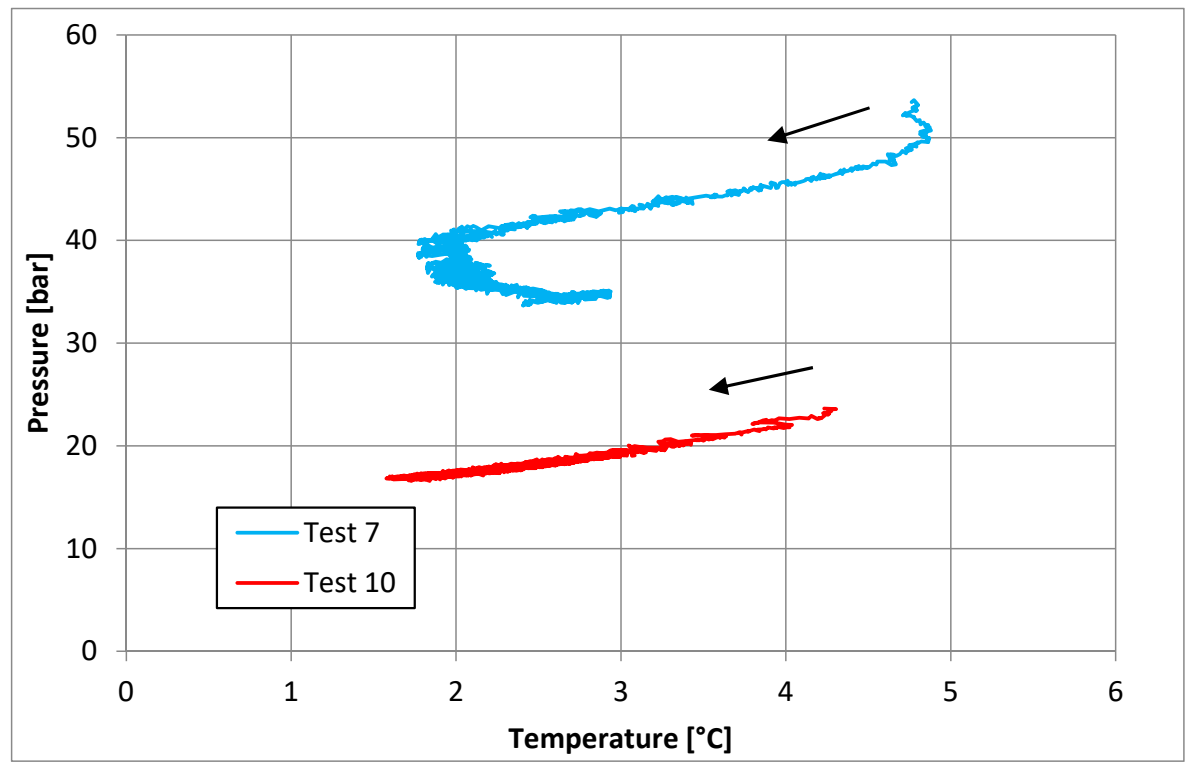

Figure 7. Comparison between Test 7, carried out using $\mathrm{CH}_{4}$, and Test 10, performed with $\mathrm{CO}_{2}$.

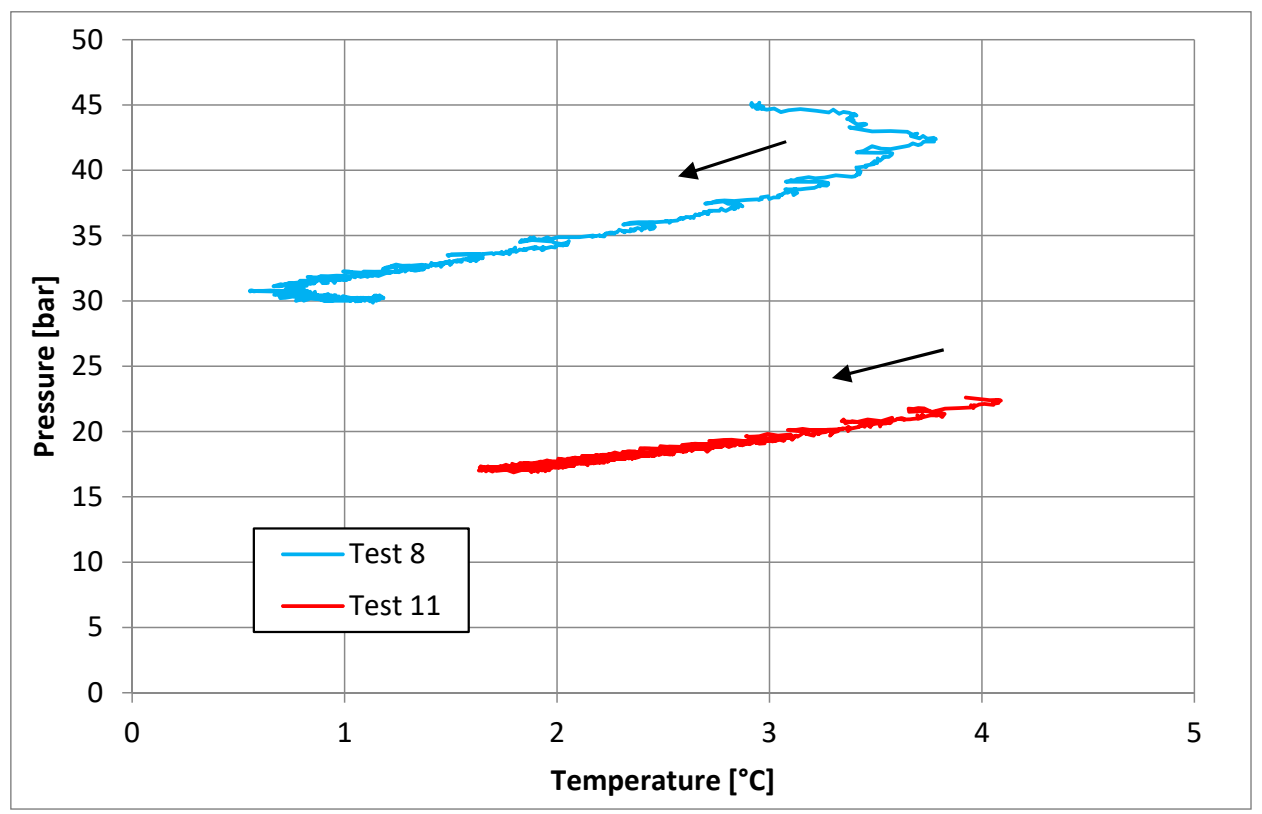

Figure 8. Comparison between Test 8, carried out using $\mathrm{CH}_{4}$, and Test 11 , performed with $\mathrm{CO}_{2}$. 


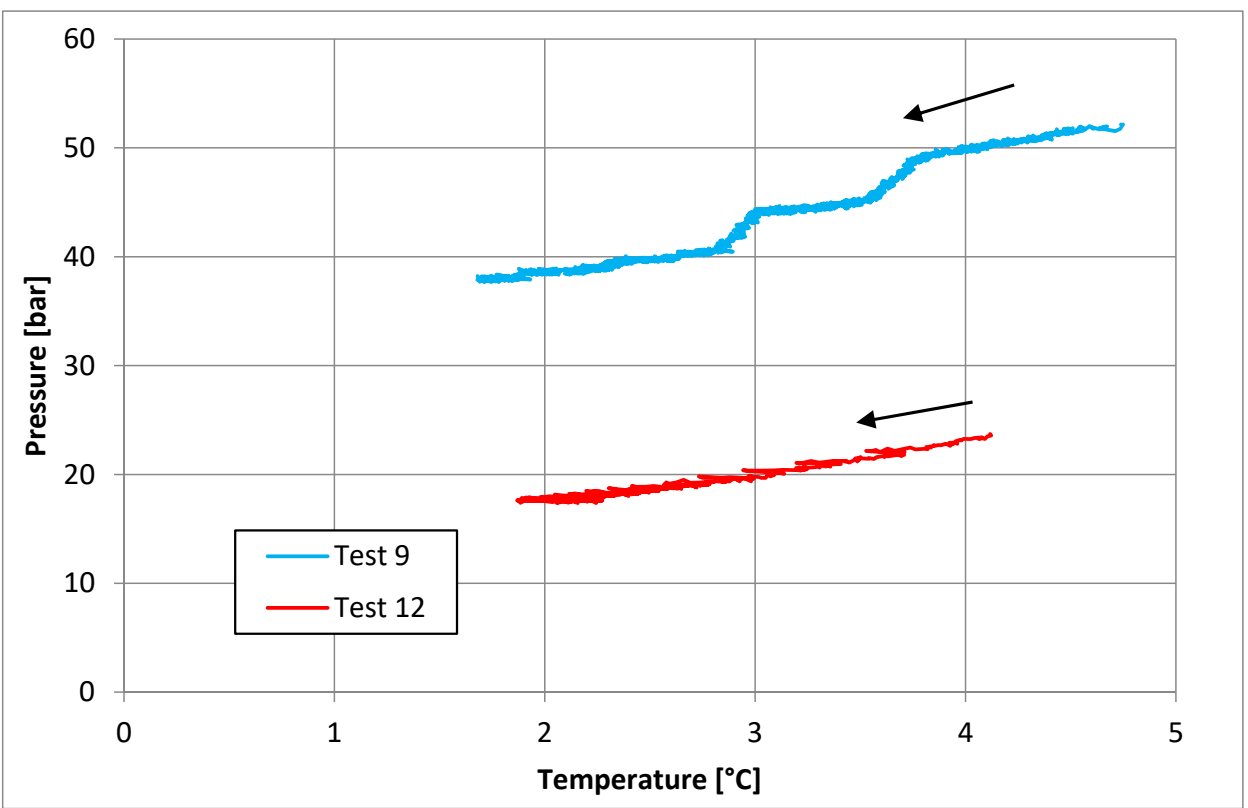

Figure 9. Comparison between Test 9, carried out using $\mathrm{CH}_{4}$, and Test 12, performed with $\mathrm{CO}_{2}$.

Table 4. Parameters related to Test 7 (with $\mathrm{CH}_{4}$ ) and Test 10 (with $\mathrm{CO}_{2}$ ).

\begin{tabular}{cccc}
\hline Parameters & Test 7 & Test 10 & Measure Units \\
\hline $\mathrm{Pi}$ & 53.47 & 23.63 & $\mathrm{bar}$ \\
$\mathrm{Ti}$ & 4.76 & 4.23 & ${ }^{\circ} \mathrm{C}$ \\
$\mathrm{Pf}$ & 33.09 & 16.73 & $\mathrm{bar}$ \\
$\mathrm{Tf}$ & 2.39 & 1.80 & ${ }^{\circ} \mathrm{C}$ \\
$\mathrm{Zi}$ & 0.85 & 0.89 & - \\
$\mathrm{Zf}$ & 0.90 & 0.93 & - \\
$\mathrm{mol}_{\text {INJ }}$ & 0.666 & 0.217 & $\mathrm{~mol}$ \\
$\mathrm{~mol}_{\text {HYD }}$ & 0.299 & 0.084 & $\mathrm{~mol}$ \\
$\mathrm{~mol}_{\text {DISS }}$ & - & 0.005 & $\mathrm{~mol}$ \\
$\eta$ & 0.948 & 0.929 & - \\
\hline
\end{tabular}

Table 5. Parameters related to Test 8 (with $\mathrm{CH}_{4}$ ) and Test 11 (with $\mathrm{CO}_{2}$ ).

\begin{tabular}{cccc}
\hline Parameters & Test 8 & Test 11 & Measure Units \\
\hline $\mathrm{Pi}$ & 45.17 & 22.60 & $\mathrm{bar}$ \\
$\mathrm{Ti}$ & 2.95 & 3.92 & ${ }^{\circ} \mathrm{C}$ \\
$\mathrm{Pf}$ & 30.12 & 17.24 & $\mathrm{bar}$ \\
$\mathrm{Tf}$ & 0.93 & 1.93 & ${ }^{\circ} \mathrm{C}$ \\
$\mathrm{Zi}$ & 0.95 & 0.89 & - \\
$\mathrm{Zf}$ & 0.91 & 0.93 & - \\
$\mathrm{mol}_{\text {INJ }}$ & 0.535 & 0.217 & $\mathrm{~mol}$ \\
$\mathrm{~mol}_{\text {HYD }}$ & 0.215 & 0.082 & $\mathrm{~mol}$ \\
$\mathrm{~mol}_{\text {DISS }}$ & - & 0.005 & $\mathrm{~mol}$ \\
$\eta$ & 0.948 & 0.901 & - \\
\hline
\end{tabular}


Table 6. Parameters related to Test 9 (with $\mathrm{CH}_{4}$ ) and Test 12 (with $\mathrm{CO}_{2}$ ).

\begin{tabular}{cccc}
\hline Parameters & Test $\mathbf{9}$ & Test 12 & Measure Units \\
\hline $\mathrm{Pi}$ & 52.14 & 24.38 & $\mathrm{bar}$ \\
$\mathrm{Ti}$ & 3.48 & 2.89 & ${ }^{\circ} \mathrm{C}$ \\
$\mathrm{Pf}$ & 38.21 & 17.62 & $\mathrm{bar}$ \\
$\mathrm{Tf}$ & 0.86 & 2.26 & ${ }^{\circ} \mathrm{C}$ \\
$\mathrm{Zi}$ & 0.84 & 0.88 & - \\
$\mathrm{Zf}$ & 0.88 & 0.92 & - \\
$\mathrm{mol}_{\text {INJ }}$ & 0.682 & 0.243 & $\mathrm{~mol}$ \\
$\mathrm{~mol}_{\mathrm{HYD}}$ & 0.221 & 0.089 & $\mathrm{~mol}$ \\
$\mathrm{~mol}_{\mathrm{DISS}}$ & - & 0.005 & $\mathrm{~mol}$ \\
$\eta$ & 0.747 & 0.882 & - \\
\hline
\end{tabular}

Experiments shown in this section assumed the same trend as the previous group of tests. Experiments conducted with carbon dioxide are more ordered and so repeatable than tests carried out with methane, which show some differences in interest if compared with tests performed in the absence of salt. In both Figures 7 and 8, the last part of the diagram describes an inversion of temperature; however, pressure continued decreasing, proving that hydrate formation was taking place. Considering that no heat was introduced from the external environment, this behavior proves the formation of another hydrate nucleation point, with the consequent heat production. The first part of the methane hydrate formation curve in Figure 8 shows at the same time a decrease in pressure and an increase in temperature. It confirms the presence of several nucleation sites inside the reactor: while the first nuclei had already begun the agglomeration phase, other nuclei are formed and, consequently, produce heat, generating a pressure-temperature trend unusual for hydrate formation. Therefore, hydrate formation in correspondence with different nucleation sites started at different time periods, causing local and sudden temperature increases while, considering the overall tendency, the system continuously moved toward reaching the equilibrium condition for hydrate and the thermal equilibrium with the thermostatic bath and, thus, the reactor walls. This explains the unusual trend in the P-T diagram, which was more and more pronounced with the increase in initial pressure and, thus, the sand pores saturation degree [25]. From Tables 4-6, it clearly appears that this behavior did not affect the process' efficiency. In fact, both methane hydrate formation tests with this characteristic had an efficiency equal to 0.948 , while the third experiments, whose trend was nearer to the ideal one, reached a value of 0.747 . On the contrary, efficiency values of tests carried out with carbon dioxide are close to each other and are in the range 0.882-0.929. Finally, considering the temperature range where the formation process of both compounds was observed, the P-T range of methane and carbon dioxide hydrate was more comparable and the thermodynamic area existing between their respective diagrams remained stable. This similarity was not observed in tests belonging to the first group where, with the varying of temperature, this distance changed significantly. Figures 5 and 6 clearly show this tendency: P-T diagrams of methane and carbon dioxide assumed very different trends and, in particular, their respective distance was higher in correspondence with the more elevated temperature values registered during the tests, while it suffered a contraction with the decrease in temperature. Regarding the first group of tests, only the comparison between Test 1 and Test 4 did not show clearly this variation in distance; however, it occurred also in this case, with a contraction greater than $20 \%$ (even in this case registered in correspondence with the lowest temperature values). On the contrary, in this section, all comparison made between tests carried out with methane and tests realized with carbon dioxide exhibited a particularly similar trend among the respective P-T diagrams. Even in this case, only one exception needs to be deepened, namely the comparison between Test 7 (made with $\mathrm{CH}_{4}$ ) and Test 10 (made with $\mathrm{CO}_{2}$ ), shown in Figure 7. Here, the difference in pressure observed at the lowest temperature values may be considered significantly lower than the same parameter measured at higher temperatures. However, this variation is due to a significative temperature increase, which depended on the growth of a new nucleation site. Without considering 
the contribution of this local nucleation point, the $\mathrm{P}-\mathrm{T}$ trend of methane hydrate would have remained practically the same as that of carbon dioxide hydrate.

\subsection{Tests Carried out in Presence of Salt, with a Concentration of $37 \mathrm{~g} / \mathrm{L}$}

This paragraph shows all experiments carried out with a salinity concentration equal to $37 \mathrm{~g} / \mathrm{L}$. As in the previous sections, tests are illustrated with Tables 7-9 and three Figures 10-12, each one for a pair of $\mathrm{CH}_{4}$ and $\mathrm{CO}_{2}$ tests.

Table 7. Parameters related to Test 13 (with $\mathrm{CH}_{4}$ ) and Test 16 (with $\mathrm{CO}_{2}$ ).

\begin{tabular}{cccc}
\hline Parameters & Test 13 & Test 16 & Measure Units \\
\hline $\mathrm{Pi}$ & 54.00 & 32.46 & $\mathrm{bar}$ \\
$\mathrm{Ti}$ & 6.37 & 6.74 & ${ }^{\circ} \mathrm{C}$ \\
$\mathrm{Pf}$ & 42.00 & 27.87 & $\mathrm{bar}$ \\
$\mathrm{Tf}$ & 0.76 & 3.32 & ${ }^{\circ} \mathrm{C}$ \\
$\mathrm{Zi}$ & 0.84 & 0.79 & - \\
$\mathrm{Zf}$ & 0.87 & 0.82 & - \\
$\mathrm{mol}_{\text {INJ }}$ & 0.699 & 0.444 & $\mathrm{~mol}$ \\
mol $_{\text {HYD }}$ & 0.191 & 0.075 & $\mathrm{~mol}$ \\
mol $_{\text {DISS }}$ & - & 0.005 & $\mathrm{~mol}$ \\
$\eta$ & 0.696 & 0.624 & - \\
\hline
\end{tabular}

Table 8. Parameters related to Test 14 (with $\mathrm{CH}_{4}$ ) and Test 17 (with $\mathrm{CO}_{2}$ ).

\begin{tabular}{cccc}
\hline Parameters & Test $\mathbf{1 4}$ & Test $\mathbf{1 7}$ & Measure Units \\
\hline $\mathrm{Pi}$ & 54.48 & 32.01 & $\mathrm{bar}$ \\
$\mathrm{Ti}$ & 5.43 & 6.66 & ${ }^{\circ} \mathrm{C}$ \\
$\mathrm{Pf}$ & 39.12 & 26.34 & $\mathrm{bar}$ \\
$\mathrm{Tf}$ & 1.63 & 1.68 & ${ }^{\circ} \mathrm{C}$ \\
$\mathrm{Zi}$ & 0.84 & 0.80 & - \\
$\mathrm{Zf}$ & 0.88 & 0.83 & - \\
$\mathrm{mol}_{\mathrm{INJ}}$ & 0.710 & 0.437 & $\mathrm{~mol}$ \\
$\mathrm{~mol}_{\mathrm{HYD}}$ & 0.242 & 0.089 & $\mathrm{~mol}$ \\
$\mathrm{~mol}_{\text {DISS }}$ & - & 0.005 & $\mathrm{~mol}$ \\
$\eta$ & 0.730 & 0.528 & - \\
\hline
\end{tabular}

Table 9. Parameters related to Test 15 (with $\mathrm{CH}_{4}$ ) and Test 18 (with $\mathrm{CO}_{2}$ ).

\begin{tabular}{cccc}
\hline Parameters & Test 15 & Test 18 & Measure Units \\
\hline $\mathrm{Pi}$ & 52.63 & 29.94 & $\mathrm{bar}$ \\
$\mathrm{Ti}$ & 4.53 & 6.69 & ${ }^{\circ} \mathrm{C}$ \\
$\mathrm{Pf}$ & 41.14 & 24.26 & $\mathrm{bar}$ \\
$\mathrm{Tf}$ & 1.52 & 3.59 & ${ }^{\circ} \mathrm{C}$ \\
$\mathrm{Zi}$ & 0.84 & 0.81 & - \\
$\mathrm{Zf}$ & 0.87 & 0.85 & - \\
$\mathrm{mol}_{\text {INJ }}$ & 0.684 & 0.401 & $\mathrm{~mol}$ \\
$\mathrm{~mol}_{\mathrm{HYD}}$ & 0.186 & 0.088 & $\mathrm{~mol}$ \\
$\mathrm{~mol}_{\mathrm{DISS}}$ & - & 0.005 & $\mathrm{~mol}$ \\
$\eta$ & 0.694 & 0.716 & - \\
\hline
\end{tabular}




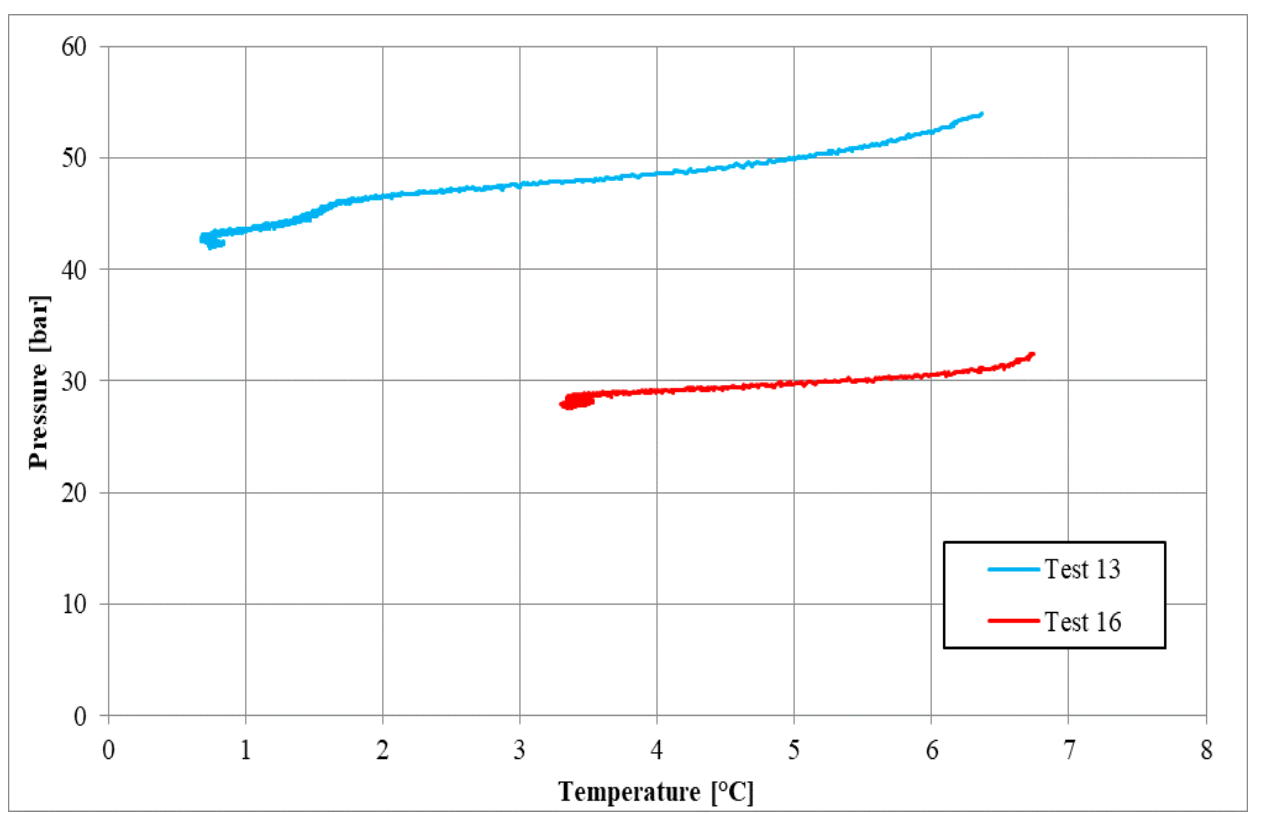

Figure 10. Comparison between Test 13 , carried out using $\mathrm{CH}_{4}$, and Test 16 , performed with $\mathrm{CO}_{2}$.

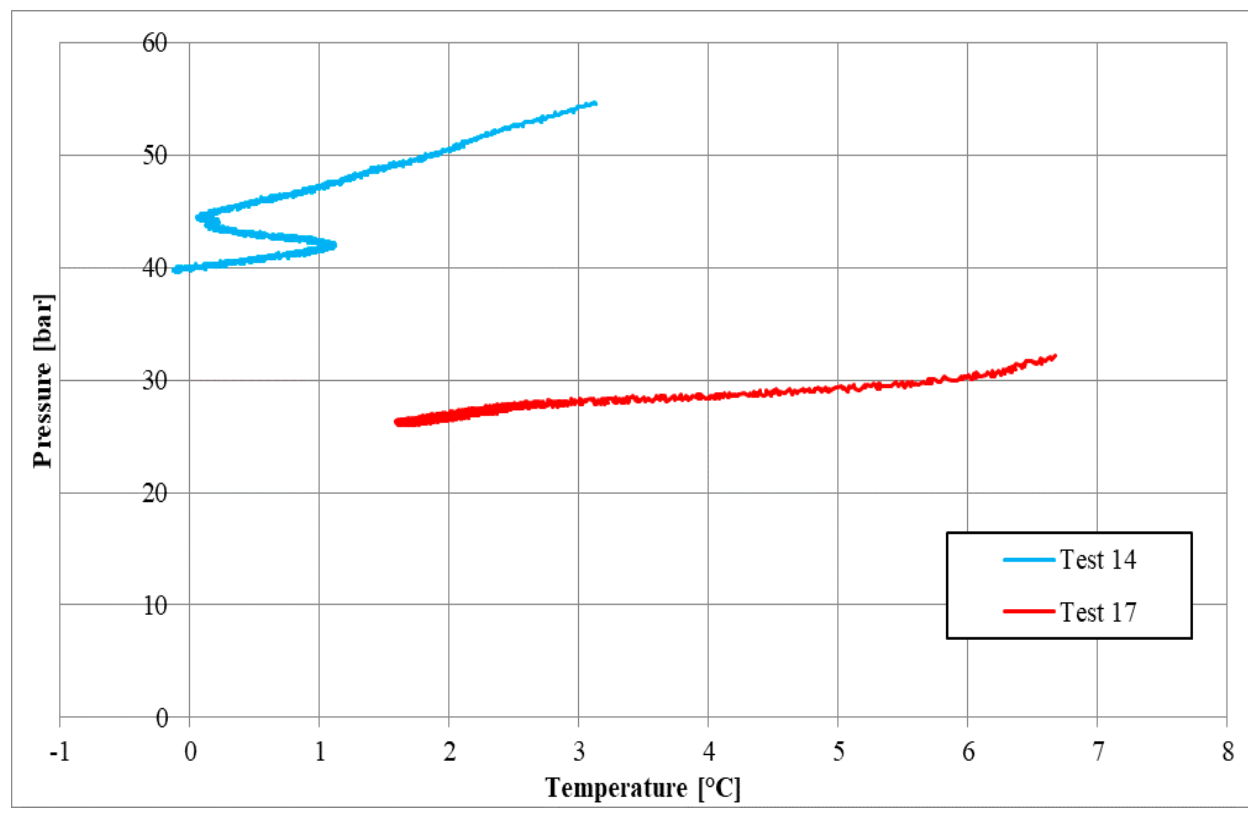

Figure 11. Comparison between Test 14 , carried out using $\mathrm{CH}_{4}$, and Test 17 , performed with $\mathrm{CO}_{2}$.

The most important difference existing between tests belonging to the present section and the previous consists in differences found in terms of efficiency. Methane hydrate formation experiments registered efficiency values in the range $0.912-0.989$ in the absence of sodium chloride and in the range $0.747-0.948$ with a salt concentration of $32 \mathrm{~g} / \mathrm{L}$; here, efficiency moved from 0.694 (Test 15) to 0.73 (Test 14). As far as tests carried out with carbon dioxide, the same aspect was verified: efficiency range was $0.789-0.909$ in the absence of salt and $0.882-0.929$ with $32 \mathrm{~g} / \mathrm{L}$, while the use of $37 \mathrm{~g} / \mathrm{L}$ of salt led to an efficiency reduction, which brought values in the range 0.528-0.624. 


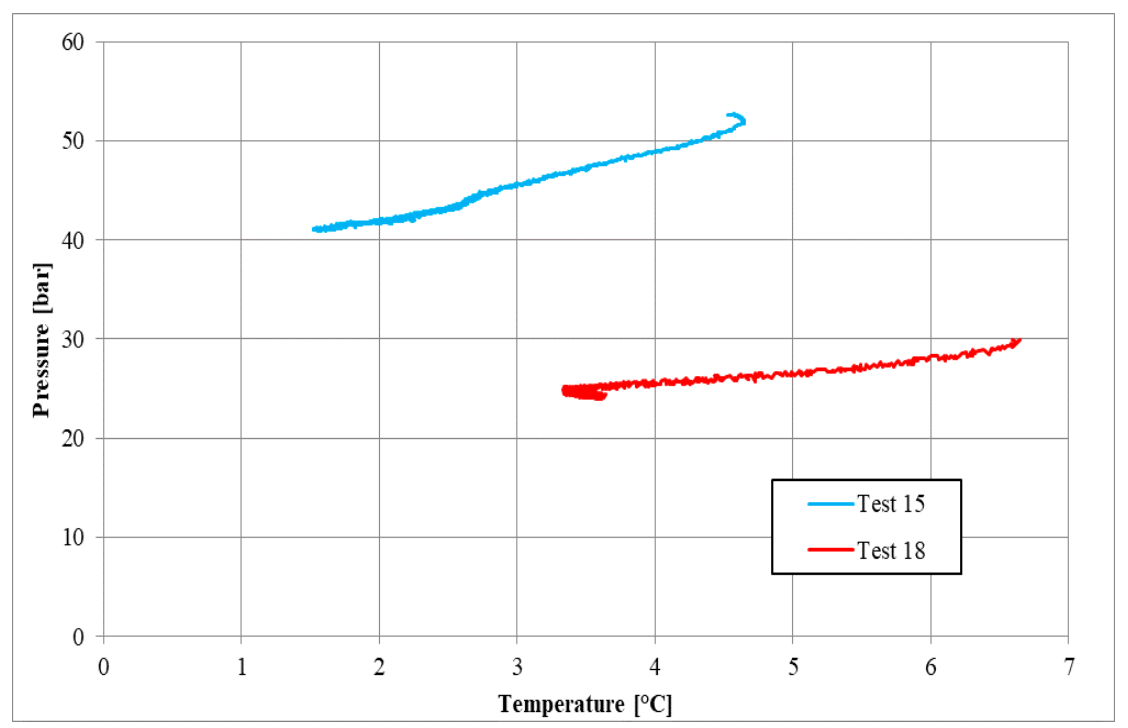

Figure 12. Comparison between Test 15 , carried out using $\mathrm{CH}_{4}$, and Test 18 , performed with $\mathrm{CO}_{2}$.

The results prove that the efficiency decrease was not caused by salt dissolution in water. There are no significant differences between experiments carried out in the absence of salt and tests with a concentration around $32 \mathrm{~g} / \mathrm{L}$. Even $\mathrm{CO}_{2}$ hydrate formation tests assumed a higher efficiency with this salt concentration than in pure demineralized water. Thus, the reason for such an efficiency decrease lies in the greater initial pressure value. While this paper describes the first experimental campaign, carried out with the experimental apparatus described previously, where $\mathrm{CO}_{2}$ hydrate formation tests were studied and classified for their efficiency, in the case of methane, similar characteristics were analyzed and studied previously and now permit us to enrich our conclusions. In Rossi et al. (2019) [25], nine methane hydrate formation tests were carried out and divided into three groups in terms of their saturation degree: 10, 20 and 30\%. In the following table, these tests are described by showing their initial pressure $(\mathrm{Pi})$, final pressure $(\mathrm{Pf})$, corresponding to the end of hydrate formation phase, and their efficiency, calculated with the same method used for experiments previously described.

From Table 10, the effect of initial pressure on the process efficiency clearly appears. While experiments carried out with a starting value lower than 50 bar have an efficiency higher than 0.9 , tests starting with a pressure higher than 60 bar show a significantly lower efficiency (in the range $0.50-0.55$, with the only exception being Test 4 , where the efficiency is anyway lower than Tests 1-3). Comparing pairs $\left(\mathrm{P}_{\mathrm{i}}-\eta\right)$ between tests shown in Table 10 and tests described in the present work, the influence of initial pressure on the process efficiency clearly appears.

Table 10. Efficiency calculated for $\mathrm{CH}_{4}$ hydrate formation tests already studied in Rossi et al. (2019) [25].

\begin{tabular}{cccc}
\hline Test no & Pi [bar] & Pf [bar] & $\boldsymbol{\eta}$ \\
\hline 1 & 45.52 & 34.72 & 0.967 \\
2 & 44.60 & 31.65 & 0.911 \\
3 & 43.19 & 30.03 & 0.989 \\
4 & 65.81 & 46.36 & 0.840 \\
5 & 54.59 & 39.55 & 0.730 \\
6 & 59.12 & 51.17 & 0.663 \\
7 & 68.70 & 62.71 & 0.500 \\
8 & 67.77 & 58.16 & 0.507 \\
9 & 70.08 & 60.65 & 0.540 \\
\hline
\end{tabular}

As in the previous section, the similarity between $\mathrm{P}-\mathrm{T}$ diagrams belonging to tests carried out with methane and tests carried out with carbon dioxide is significantly more pronounced than in tests 
realized in pure demineralized water. Here, the comparison between Test $14\left(\mathrm{CH}_{4}\right)$ and Test $17\left(\mathrm{CO}_{2}\right)$ needs to be deepened. In the presence of relatively low temperatures, the methane diagram seemed to approach the respective carbon dioxide diagram. However, the methane curve lowering occurred in correspondence with temperature values that were not reached during the $\mathrm{CO}_{2}$ formation experiment. Moreover, even in this case, the hydrate production and growth from a new nucleation site led to a temporary temperature increase; meanwhile, pressure continued to decrease.

Even in this section, methane P-T diagrams during hydrate formation did not exactly follow the ideal one, particularly in Test 14 . As explained previously, the trend depends on the non-simultaneous formation of new hydrate nuclei and their subsequent growth. This aspect is affected by initial pressure (even in this case, see Rossi et al. (2019) [25]) but has no relevant consequences for the process efficiency. Demonstration of it is the efficiency value measured in Test 14 (0.73), which represents the highest efficiency calculated for methane hydrate formation tests carried out with $37 \mathrm{~g} / \mathrm{L}$ of sodium chloride.

\subsection{Evaluation of Dimensions of the Area Useful for $\mathrm{CH}_{4} / \mathrm{CO}_{2}$ Replacement Strategies in Function of Salinity}

In this last section, the effect of salinity on the thermodynamic region, existing between the methane and carbon dioxide equilibrium curve, was explored. The aim of this paragraph is to show how sodium chloride's presence may improve the $\mathrm{CH}_{4} / \mathrm{CO}_{2}$ replacement efficiency. A greater distance between methane and carbon dioxide $\mathrm{P}-\mathrm{T}$ diagrams guarantees the possibility of injecting $\mathrm{CO}_{2}$ inside the NGH reservoir with thermodynamic conditions more distant from the methane hydrate stability zone than cases where those curves are closer together. This allows us to reach a higher $\mathrm{CH}_{4}$ hydrate dissociation and, thus, an increase in the replacement rate. Here, we propose an analysis of differences between $\mathrm{CH}_{4}$ and $\mathrm{CO}_{2}$ pressure values in the function of temperature. Considering that hydrate formation is a stochastic process, tests started and finished at different temperature values from each other, so that comparison has been possible in a limited temperature range, between 2.0 and $3.8^{\circ} \mathrm{C}$. In this range, the pressure difference was calculated at each $0.2^{\circ} \mathrm{C}$. With the aim of showing the worst configuration possible for proving our thesis, for each temperature value considered, the lowest $\mathrm{CH}_{4}$ tests and the highest $\mathrm{CO}_{2}$ test pressures were taken into account; thus, the shortest distance between methane and carbon dioxide experiments was considered.

In the following table, the distance between $\mathrm{CH}_{4}$ and $\mathrm{CO}_{2}$ tests pressures is shown in the range of $2.0-3.8^{\circ} \mathrm{C}$ for all tests.

The results clearly show how sodium chloride's presence strongly affects $\Delta \mathrm{P}$; in particular, the difference between methane and carbon dioxide diagrams, evaluated in the absence of salt, is in the range of 9.4-12.41 bar, while in the other two cases, this scatter is considerably higher: 16.87-20.16 for tests carried out with $32 \mathrm{~g} / \mathrm{L}$ of salt and 15.07-19.67 for tests with $37 \mathrm{~g} / \mathrm{L}$. Thus, salt presence represents an aid for improving $\mathrm{CO}_{2}$ replacement strategies, even if it is an inhibitor of hydrates, independently of the gaseous species continuing inside ice structures. While this aspect is well shown in Table 11, what happened with the increase in salt concentration does not appear clearly in the table. In particular, $\Delta \mathrm{P}$ values in tests carried out with respectively $32 \mathrm{~g} / \mathrm{L}$ and $37 \mathrm{~g} / \mathrm{L}$ are very similar and, with the only exception being values measured at 3.4 and $3.0^{\circ} \mathrm{C}$, the pressure range is higher in the first group $(32 \mathrm{~g} / \mathrm{L})$. This result is in contrast with previous results. The reason has to be found in the amplitude of the temperature range taken into account: for values higher than $4.0^{\circ} \mathrm{C}$, parameter $\Delta \mathrm{P}$ is consistently higher in tests carried out with $37 \mathrm{~g} / \mathrm{L}$ of salt. Moreover, the $\mathrm{CH}_{4}$ test used for defining pressure for the third group is significantly far from other two tests, which show higher pressure values at the same temperature. This non-negligible distribution between tests belonging to the same group did not appear in $32 \mathrm{~g} / \mathrm{L}$ groups; so, in Table 11, parameter $\Delta \mathrm{P}$ for tests carried out with a salt concentration of $37 \mathrm{~g} / \mathrm{L}$ appears less pronounced than its real value. 
Table 11. Pressure difference between $\mathrm{CH}_{4}$ and $\mathrm{CO}_{2}$ formation tests at different salinity concentrations.

\begin{tabular}{|c|c|c|c|c|c|c|c|c|c|}
\hline \multirow[b]{2}{*}{$\begin{array}{c}\mathrm{T} \\
\left({ }^{\circ} \mathrm{C}\right)\end{array}$} & \multicolumn{3}{|c|}{ Tests without Salt } & \multicolumn{3}{|c|}{ Tests with $32 \mathrm{~g} / \mathrm{L}$ of Salt } & \multicolumn{3}{|c|}{ Tests with $37 \mathrm{~g} / \mathrm{L}$ of Salt } \\
\hline & $\begin{array}{l}\mathrm{P}_{\mathrm{CH}_{4}} \\
\text { (bar) }\end{array}$ & $\begin{array}{l}\mathrm{P}_{\mathrm{CO}_{2}} \\
\text { (bar) }\end{array}$ & $\begin{array}{c}\Delta \mathrm{P} \\
\text { (bar) }\end{array}$ & $\begin{array}{l}\mathrm{P}_{\mathrm{CH}_{4}} \\
\text { (bar) }\end{array}$ & $\begin{array}{l}\mathrm{P}_{\mathrm{CO}_{2}} \\
\text { (bar) }\end{array}$ & $\begin{array}{c}\Delta \mathbf{P} \\
\text { (bar) }\end{array}$ & $\begin{array}{l}\mathrm{P}_{\mathrm{CH}_{4}} \\
\text { (bar) }\end{array}$ & $\begin{array}{l}\mathrm{P}_{\mathrm{CO}_{2}} \\
\text { (bar) }\end{array}$ & $\begin{array}{c}\Delta \mathrm{P} \\
\text { (bar) }\end{array}$ \\
\hline 3.8 & 34.90 & 22.69 & 12.21 & 42.52 & 22.36 & 20.16 & 48.34 & 28.67 & 19.67 \\
\hline 3.6 & 34.43 & 22.22 & 12.21 & 41.83 & 22.07 & 19.76 & 47.66 & 28.49 & 19.17 \\
\hline 3.4 & 33.77 & 21.36 & 12.41 & 39.54 & 21.26 & 18.28 & 47.01 & 28.37 & 18.64 \\
\hline 3.2 & 33.31 & 20.97 & 12.34 & 38.66 & 20.39 & 18.27 & 46.36 & 28.15 & 18.21 \\
\hline 3.0 & 31.88 & 20.95 & 10.93 & 37.79 & 20.35 & 17.44 & 45.67 & 28.02 & 17.65 \\
\hline 2.8 & 30.89 & 20.63 & 10.26 & 36.89 & 19.26 & 17.63 & 44.85 & 27.88 & 16.97 \\
\hline 2.6 & 30.57 & 20.31 & 10.26 & 36.42 & 18.85 & 17.57 & 43.54 & 27.87 & 15.67 \\
\hline 2.4 & 30.01 & 19.87 & 10.14 & 35.79 & 18.46 & 17.33 & 42.86 & 27.79 & 15.07 \\
\hline 2.2 & 29.13 & 19.73 & 9.40 & 35.01 & 18.14 & 16.87 & 42.36 & 26.96 & 15.40 \\
\hline 2.0 & 28.86 & 19.31 & 9.55 & 34.88 & 17.92 & 16.96 & 41.95 & 26.55 & 15.40 \\
\hline
\end{tabular}

In conclusion, the results prove how a hydrate inhibitor may play a key role during the application of $\mathrm{CO}_{2} / \mathrm{CH}_{4}$ replacement strategies in NGH reservoirs; in particular, sodium chloride is able to increase the thermodynamic area where carbon dioxide hydrate formation and stability is guaranteed while the contrary happens for methane hydrate. Future works will be necessary for a better analysis and to catalogue parameter $\Delta \mathrm{P}$ in the function of salt concentration. Moreover, this inhibitor is characterized by very low costs and does not affect the external environment.

\subsection{A Brief Comparison with Data Present in the Literature}

Finally, results produced for methane and carbon dioxide hydrate formation were briefly compared with those present in the literature (see Tables 12 and 13), in order to confirm their truthfulness. As far as results carried out in pure demineralized water, a direct evaluation was already carried out via comparison with theoretical values, produced with CSM-HYD software.

Table 12. Methane hydrate equilibrium data in presence of $\mathrm{NaCl}$, currently available in the literature.

\begin{tabular}{cccc}
\hline Temperature $\left({ }^{\circ} \mathbf{C}\right)$ & Pressure (bar) & $\mathbf{N a C l}(\mathbf{w t} \%)$ & Reference \\
\hline 0.2 & 3.2 & 5 & {$[65]$} \\
0.7 & 3.31 & 5 & {$[65]$} \\
1.1 & 3.58 & 5 & {$[66]$} \\
1.2 & 3.22 & 10 & {$[66]$} \\
2.1 & 3.73 & 3.35 & {$[67]$} \\
3.3 & 3.94 & 3 & {$[65]$} \\
4.4 & 5 & 10 & {$[66]$} \\
5.3 & 4.85 & 3 & {$[65]$} \\
5.9 & 6.03 & 10 & {$[66]$} \\
6.6 & 9.13 & 10.47 & {$[67]$} \\
6.9 & 6.31 & 5 & {$[65]$} \\
8.1 & 10.59 & 10.47 & {$[67]$} \\
10.6 & 12.73 & 10.47 & {$[67]$} \\
\hline
\end{tabular}

In this work, two different salt concentrations were used, or $30 \mathrm{~g} / \mathrm{L}$ and $37 \mathrm{~g} / \mathrm{L}$. To better compare the results here produced with those present in the literature, these concentrations are reported in weight percent and are respectively 3.0 and $3.7 \mathrm{wt} \%$.

Concerning methane, experiments carried out with $3.0 \mathrm{wt} \%$ sodium chloride reached equilibrium at temperature values in the range $0.86-2.39^{\circ} \mathrm{C}$ and pressure values equal to $30.12-38.21$ bar. On the other hand, tests having $3.7 \mathrm{wt} \%$ salt stabilized for temperatures of around $0.76-1.63^{\circ} \mathrm{C}$ and pressures in the range $39.12-42$ bar.

Taking into account the final temperature values reached in all tests, the comparison with such data may be performed with the first experiments in Table 12, where methane hydrate equilibrium was observed at temperature values in the range $0.2-3.3^{\circ} \mathrm{C}$, while the corresponding pressure values were in the range $3.2-3.94$ bar. 
Table 13. Carbon dioxide hydrate equilibrium data in presence of $\mathrm{NaCl}$, currently available in the literature.

\begin{tabular}{cccc}
\hline Temperature $\left({ }^{\circ} \mathbf{C}\right)$ & Pressure (bar) & $\mathbf{N a C l}$ conc. & Reference \\
\hline 1.3 & 1.37 & $5 \mathrm{wt} \%$ & {$[66]$} \\
1.3 & 1.83 & $5 \mathrm{wt} \%$ & {$[66]$} \\
1.4 & 1.74 & $0.009 \mathrm{mf}$ & {$[68]$} \\
1.4 & 1.69 & $0.5 \mathrm{~mol} / \mathrm{L}$ & {$[69]$} \\
2.3 & 1.88 & $0.009 \mathrm{mf}$ & {$[68]$} \\
3 & 3.19 & $2 \mathrm{~mol} / \mathrm{L}$ & {$[69]$} \\
3.7 & 3.53 & $2 \mathrm{~mol} / \mathrm{L}$ & {$[69]$} \\
4 & 2.12 & $0.009 \mathrm{mf}$ & {$[68]$} \\
4.2 & 2.74 & $1 \mathrm{~mol} / \mathrm{L}$ & {$[69]$} \\
4.8 & 2.15 & $0.009 \mathrm{mf}$ & {$[68]$} \\
5.5 & 2.21 & $0.009 \mathrm{mf}$ & {$[68]$} \\
6.2 & 3.38 & $1 \mathrm{~mol} / \mathrm{L}$ & {$[69]$} \\
7.1 & 3.73 & $5 \mathrm{wt} \%$ & {$[66]$} \\
\hline
\end{tabular}

The same similarity was verified for carbon dioxide hydrate. In such a case, the presence of $3 \mathrm{wt} \%$ sodium chloride led to thermodynamic equilibrium conditions at around $1.8-2.26{ }^{\circ} \mathrm{C}$ and 16.73-17.72 bar, while, in the presence of $3.7 \mathrm{wt} \%$ salt, values measured were $1.68-3.59{ }^{\circ} \mathrm{C}$ and 24.26-27.87 bar. The following table summarizes some phase equilibrium data for carbon dioxide hydrate in the presence of sodium chloride, already present in the literature.

Thermodynamic equilibrium conditions feasible for a comparison with results here registered are related to the temperature range of $1.3-3.7^{\circ} \mathrm{C}$, whose corresponding pressure values are equal to 1.69-3.53. In such a case, while the lower values are completely comparable, the upper values are slightly higher than the results shown in Sections 3.2 and 3.3. However, the present comparison highlighted a high degree of similarity between the results produced in experiments here described and equilibrium data already present in the literature.

\section{Conclusions}

The present paper describes an experimental work focused on analyzing the effect of sodium chloride's presence on the $\mathrm{CO}_{2} / \mathrm{CH}_{4}$ exchange process in NGH reservoirs. Using three different salt concentrations (corresponding to 0,30 and $37 \mathrm{~g} / \mathrm{L}$ ), 18 hydrate formation tests were carried out-six for each salinity value. In particular, all groups were composed by three methane hydrate and three carbon dioxide formation tests. Regarding experiments involving methane, results were then compared with previous research, in order to better comprehend the hydrate formation process in a lab-scale reactor. From these results, the inhibitor effect of sodium chloride clearly appeared, on both hydrate types. However, this disadvantageous effect mainly involved methane hydrate. This led to an increase in the region existing between the pressure-temperature diagrams of these two compounds during the hydrate formation phase, which means the possibility of moving thermodynamic conditions farther from methane hydrate stability zone and, at the same time, ensuring the possibility of forming $\mathrm{CO}_{2}$ hydrate. In conclusion, based on the experimental results shown in this work, sodium chloride may be considered an aid for increasing the $\mathrm{CO}_{2}$ replacement process' efficiency. Future works will be focused on a more detailed analysis of salt's effect in terms of its concentration in water, in order to provide a greater quantity of useful data. Moreover, the same research will be repeated with different hydrate inhibitors: if the investigation of sodium chloride properties is mainly attractive due to its availability directly inside hydrate reservoirs, other inhibitor compounds might guarantee the possibility of reaching similar results, without increasing costs significantly and avoiding any environmental impact.

Author Contributions: A.M.G. designed and carried out experiments. B.C. contributed to data analysis. A.N. contributed by setting background and data acquisition. F.R. supervised the research activities. All authors have read and agreed to the published version of the manuscript. 
Funding: The present experimental research was funded by the PRIN Project entitled "Methane recovery and carbon dioxide disposal in natural gas hydrate reservoirs".

Acknowledgments: The authors would like to acknowledge the Italian Ministry of University and Scientific Research and University of Perugia for financially supporting the PRIN project.

Conflicts of Interest: The authors declare no conflict of interest. The founding sponsors had no role in the design of the study; in the collection, analyses, or interpretation of data; in the writing of the manuscript; or in the decision to publish results.

\section{References}

1. Sloan, E.D.; Koh, C.A. Clathrate Hydrates of Natural Gases, 3rd ed.; CRC Press: Boca Raton, FL, USA, 2008.

2. Makogon, Y.F. Natural gas hydrates-A promising source of energy. J. Nat. Gas Sci. Eng. 2010, 2, 49-59. [CrossRef]

3. Makogon, Y.F.; Holditch, S.A.; Makogon, T.Y. Natural gas-hydrates-A potential energy source for the 21st Century. J. Pet. Sci. Eng. 2007, 56, 14-31. [CrossRef]

4. Makogon, Y.F.; Holste, J.C.; Holditch, S.A. Natural gas hydrates and global change. In Proceedings of the Eighth International Offshore and Polar Engineering Conference, Montreal, QC, Canada, 24-29 May 1998; Volume 1, pp. 73-74.

5. Ma, R.; Zhong, H.; Liu, J.; Zhong, J.; Yan, Y.; Zhang, J.; Xu, J. Molecular Insights into Cage Occupancy of Hydrogen Hydrate: A Computational Study. Processes 2019, 7, 699. [CrossRef]

6. Englezos, P. Clathrate hydrates. Ind. Eng. Chem. Res. 1993, 32, 1251-1274. [CrossRef]

7. Stolper, D.A.; Lawson, M.; Davis, C.L.; Ferreira, A.A.; Neto, E.V.S.; Ellis, G.S.; Lewan, M.D.; Martini, A.M.; Tang, Y.; Sessions, A.L.; et al. Formation temperatures of thermogenic and biogenic methane. Science 2014, 344, 1500-1503. [CrossRef]

8. Gray, N.D.; Sherry, A.; Larter, S.R.; Erdmann, M.; Leyris, J.; Liengen, T.; Beeder, J.; Head, I.M. Biogenic methane production in formation waters from a large gas field in the North Sea. Extremophiles 2009, 13, 511-519. [CrossRef]

9. Martini, A.M.; Walter, L.M.; Budai, J.M.; Ku, T.C.W.; Kaiser, C.J.; Schoell, M. Genetic and temporal relations between formation waters and biogenic methane: UpperDevonian Antrim Shale, Michigan Basin, USA. Geochim. Cosmochim. Acta 1998, 62, 1699-1720. [CrossRef]

10. Whiticar, M.J.; Faber, E.; Schoell, M. Biogenic methane formation in marine and fresh-water environments- $\mathrm{CO}_{2}$ reduction vs acetate fermentation isotope evidence. Geochim. Cosmochim. Acta 1986, 50, 693-709. [CrossRef]

11. Max, M.D. (Ed.) Natural Gas Hydrate in Oceanic and Permafrost Environments; Kluwer Academic Publ.: Dordrecht, The Netherlands, 2000.

12. Paull, C.; Reeburgh, W.S.; Dallimore, S.R.; Enciso, G.; Green, S.; Koh, C.A.; Kvenvolden, K.A.; Mankin, C.; Riedel, M. Realizing the Energy Potential of Methane Hydrate for the United States; National Research Council of the National Academies: Washington, DC, USA, 2010.

13. Liua, L.; Ryu, B.J.; Sunb, Z.; Wu, N.; Cao, H.; Geng, W.; Zhang, X.; Jia, Y.; Xu, C.; Guo, L.; et al. Monitoring and research on environmental impacts related to marine natural gas hydrates: Review and future perspective. J. Nat. Gas Sci. Eng. 2019, 65, 82-107. [CrossRef]

14. Ruppel, C.D.; Kessler, J.D. The interaction of climate change and methane hydrates. Rev. Geophys. 2017, 55, 126-168. [CrossRef]

15. Boswell, R.; Collett, T.S. Current perspectives on gas hydrate resources. Energy Environ. Sci. 2011, 4, 1206-1215. [CrossRef]

16. Kurihara, M.; Narita, H. Gas production from methane hydrate reservoirs. In Proceedings of the 7th International Conference on Gas Hydrates (ICGH 2011), Edingburgh, Scotland, UK, 17-21 July 2011.

17. Yamamoto, K. Overview and Introduction: Pressure core-sampling and analyses in the 2012-2013 MH21 offshore test of gas production from methane hydrates in the eastern Nankai Trough. Mar. Pet. Geol. 2015, 66, $296-309$. [CrossRef]

18. Pandey, J.S.; Daas, Y.J.; Solms, N.V. Insights into Kinetics of Methane Hydrate Formation in the Presence of Surfactants. Processes 2019, 7, 598. [CrossRef] 
19. Florusse, L.J.; Peters, C.J.; Schoonman, J.; Hester, K.C.; Koh, C.A.; Dec, S.F.; Marsh, K.N.; Sloan, E.D. Stable low-pressure hydrogen clusters stored in a binary clathrate hydrate. Science 2004, 306, 469-471. [CrossRef] [PubMed]

20. Cao, J.; Zhu, S.; Li, C.; Han, B. Integrating Support Vector Regression with Genetic Algorithm for Hydrate Formation Condition Prediction. Processes 2020, 8, 519. [CrossRef]

21. Gudmundsson, J.S. Method for Production of Gas Hydrate for Transportation and Storage. U.S. Patent 5536893, 16 July 1996.

22. Hashimoto, S.; Makino, T.; Inoue, Y.; Ohgaki, K. Three-phase equilibrium relations and hydrate dissociation enthalpies for hydrofluorocarbon hydrate systems: HFC-134a, -125, and -143a hydrates. J. Chem. Eng. Data 2010, 55, 4951-4955. [CrossRef]

23. Gambelli, A.M.; Castellani, B.; Nicolini, A.; Rossi, F. Gas hydrate formation as a strategy for $\mathrm{CH}_{4} / \mathrm{CO}_{2}$ separation: Experimental study on gaseous mixtures produced via Sabatier reaction. J. Nat. Gas Sci. Eng. 2019, 71, 102985. [CrossRef]

24. Aliev, A.; Yusifov, R.; Tairov, A.; Sarydzhanov, A.; Mirzoeva, R.; Yusifov, Y. Mathematical modelling of seawater desalination by the gas hydrate method. Theor. Found. Chem. Eng. 2011, 45, 185-189. [CrossRef]

25. Rossi, F.; Gambelli, A.M.; Sharma, D.K.; Castellani, B.; Nicolini, A.; Castaldi, M.J. Simulation of methane hydrates formation in seabed deposit and gas recovery adopting carbon dioxide replacement strategies. Appl. Therm. Eng. 2019, 148, 371-381. [CrossRef]

26. Collett, T.S.; Ginsburg, G.D. Gas hydrates in the Messoyakha gas field of the west Siberian basin-A re-examination of the geologic evidence. Int. Offshore Polar Eng. 1997, 8, 96-103.

27. Collett, T.S.; Kuuskraa, V.A. Hydrates contain vast store of world gas resources. Oil Gas J. 1998, 96, 90-95.

28. Feng, J.C.; Li, X.S.; Li, G.; Li, B.; Chen, Z.Y.; Wang, Y. Numerical investigation of hydrate dissociation performance in the South China Sea with different horizontal well configurations. Energies 2014, 7, 4813-4834. [CrossRef]

29. Li, B.; Li, G.; Li, X.S.; Chen, Z.Y.; Zhang, Y. The use of heat-assisted antigravity drainage method in the two horizontal wells in gas production from the Qilian Mountain permafrost hydrate deposits. J. Pet. Sci. Eng. 2014, 120, 141-153. [CrossRef]

30. Afzal, W.; Mohammadi, A.H.; Richon, D. Experimental measurements and predictions of dissociation conditions for methane, ethane, propane, and carbon dioxide simple hydrates in the presence of diethylene glycol aqueous solutions. J. Chem. Eng. Data 2008, 53, 663-666. [CrossRef]

31. Dong, F.; Zang, X.; Li, D.; Fan, S.; Liang, D. Experimental investigation on propane hydrate dissociation by high concentration methanol and ethylene glycol solution injection. Energy Fuels 2009, 23, 1563-1567. [CrossRef]

32. Sloan, E.D. Clathrate Hydrates of Natural Gases; Taylor \& Francis: Washington, DC, USA, 2007.

33. Gambelli, A.M.; Rossi, F. The use of sodium chloride as strategy for improving $\mathrm{CO}_{2} / \mathrm{CH}_{4}$ replacement in natural gas hydrates promoted with depressurization methods. Arab. J. Geosci. 2020, 13, 898. [CrossRef]

34. Castellani, B.; Gambelli, A.M.; Nicolini, A.; Rossi, F. Energy and Environmental Analysis of Membrane-Based $\mathrm{CH}_{4}-\mathrm{CO}_{2}$ Replacement Processes in Natural Gas Hydrates. Energies 2019, 12, 850. [CrossRef]

35. Sabil, K.M.; Duarte, A.R.C.; Zevenbergen, C.; Ahmad, M.M.; Yusup, S.; Omar, A.A.; Peters, C.J. Kinetic of formation for single carbon dioxide and mixed carbon dioxide and tetrahydrofuran hydrates in water and sodium chloride aqueous solution. Int. J. Greenh. Gas Control 2010, 4, 798-805. [CrossRef]

36. Gambelli, A.M.; Filipponi, M.; Nicolini, A.; Rossi, F. Chemical inhibitors as potential allied for $\mathrm{CO}_{2}$ replacement in gas hydrates reservoirs: Sodium chloride case study. In Proceedings of the International Multidisciplinary GeoConference: SGEM, Sofia, Bulgaria, 30 June-6 July 2019; Surveying Geology \& Mining Ecology Managment (SGEM): Sofia, Bulgaria, 2019; Volume 19, pp. 333-343. [CrossRef]

37. Kharrat, M.; Dalmazzone, D. Experimental determination of stability conditions of methane hydrate in aqueous calcium chloride solutions using high pressure differential scanning calorimetry. J. Chem. Thermodyn. 2003, 35, 1489-1505. [CrossRef]

38. Cha, M.J.; Hu, Y.; Sum, A.K. Methane hydrate phase equilibria for systems containing $\mathrm{NaCl}, \mathrm{KCl}$, and $\mathrm{NH}_{4} \mathrm{Cl}$. Fluid Phase Equilibria 2016, 413, 2-9. [CrossRef]

39. Hu, Y.; Makogon, T.Y.; Karanjkar, P.; Lee, K.H.; Lee, B.R.; Sum, A.K. Gas hydrates phase equilibria and formation from high concentration $\mathrm{NaCl}$ brines up to $200 \mathrm{MPa}$. J. Chem. Eng. Data 2017, 62, 1910-1918. [CrossRef] 
40. Javanmardi, J.; Moshfeghian, M.; Maddox, R.N. Simple method for predicting gas-hydrate-forming conditions in aqueous mixed-electrolyte solutions. Energy Fuels 1998, 12, 219-222. [CrossRef]

41. Long, Z.; Du, J.W.; Li, D.L.; Liang, D.Q. Phase equilibria of ethane hydrate in $\mathrm{MgCl}_{2}$ aqueous solutions. J. Chem. Eng. Data 2010, 55, 2938-2941. [CrossRef]

42. Englezos, P.; Ngan, Y.T. Incipient equilibrium data for propane hydrate formation in aqueous solutions of $\mathrm{NaCl}, \mathrm{KCl}$ and $\mathrm{CaCl}_{2}$. J. Chem. Eng. Data 1993, 38, 250-253. [CrossRef]

43. Uchida, T.; Ikeda, I.Y.; Takeya, S.; Ebinuma, T.; Nagao, J.; Narita, H. $\mathrm{CO}_{2}$ hydrate film formation at the boundary between $\mathrm{CO}_{2}$ and water: Effects of temperature, pressure and additives on the formation rate. J. Cryst. Growth 2002, 237-239, 383-387. [CrossRef]

44. Bradshaw, R.W.; Greathouse, J.A.; Cygan, R.T.; Simmons, B.A.; Dedrick, D.E.; Majzoub, E.H. Desalination Utilizing Clathrate Hydrates; LDRD Final Report; Sandia report SAND2007-6565; Sandia National Laboratories: Albuquerque, NM, USA, 2008.

45. Tromp, R.H.; Neilson, G.W.; Soper, A.K. Water structure in concentrated lithium chloride solutions. J. Chem. Phys. 1992, 96, 8460-8469. [CrossRef]

46. Lu, H.; Matsumoto, R.; Tsuji, Y.; Oda, H. Anion plays a more important role than cation in affecting gas hydrate stability in electrolyte solution?-A recognition from experimental results. Fluid Phase Equilibria 2001, 178, 225-232. [CrossRef]

47. Gambelli, A.M.; Rossi, F. Natural gas hydrates: Comparison between two different applications of thermal stimulation for performing $\mathrm{CO}_{2}$ replacement. Energy 2019, 172, 423-434. [CrossRef]

48. Gambelli, A.M.; Rossi, F. Investigation on effects produced by sodium chloride presence on the $\mathrm{CO}_{2}$ hydrate formation process. In Proceedings of the 2nd Conference of the Arabian Journal of Geosciences, Sousse, Tunisia, 25-28 November 2019.

49. Ng, H.J.; Robinson, D.B. New Developments in the Measurement and Prediction of Hydrate Formation for Processing Needs. Ann. N. Y. Acad. Sci. 1994, 715, 450-462. [CrossRef]

50. Javanmardi, J.; Ayatollahi, S.; Motealleh, R.; Moshfeghian, M. Experimental measurement and modelling of R22 $\left(\mathrm{CHClF}_{2}\right)$ hydrates in mixtures of acetone + water. J. Chem. Eng. Data 2004, 49, 886-889. [CrossRef]

51. Maekawa, T. Equilibrium conditions for clathrate hydrates formed from carbon dioxide or ethane in the presence of aqueous solutions of 1,4-dioxane and 1,3-dioxolane. Fluid Phase Equilibria 2014, 384, 95-99. [CrossRef]

52. De Deugd, R.M.; Jager, M.D.; de Swaan Arons, J. Mixed Hydrates of Methane and Water-Soluble Hydrocarbons Modeling of Empirical Results. AIChE J. 2001, 47, 693-704. [CrossRef]

53. Jager, M.D.; de Deugd, R.M.; Peters, C.J.; Arons, J.S.; Sloan, E.D. Experimental determination and modelling of structure II hydrates in mixtures of methane + water + 1,4-dioxane. Fluid Phase Equilibria 1999, 165, $209-223$. [CrossRef]

54. Maekawa, T. Equilibrium conditions of clathrate hydrates formed from carbon dioxide and aqueous acetone solutions. Fluid Phase Equilibria 2011, 303, 76-79. [CrossRef]

55. Sun, Z.G.; Fan, S.S.; Guo, K.H.; Shi, L.; Wang, R.Z. Equilibrium hydrate formation conditions for methylcyclohexane with methane and a ternary gas mixture. Fluid Phase Equilibria 2002, 198, $293-298$. [CrossRef]

56. Maekawa, T. Equilibrium conditions for clathrate hydrates formed from methane and aqueous propanol solutions. Fluid Phase Equilibria 2008, 267, 1-5. [CrossRef]

57. Ostergaard, K.K.; Tohidi, B.; Anderson, R.; Todd, A.C.; Danesh, A. Can 2-propanol form clathrate hydrates? Ind. Eng. Chem. Res. 2002, 41, 2064-2068. [CrossRef]

58. Ohmura, R.; Takeya, S.; Uchida, T.; Ebinuma, T. Clathrate hydrate formed with methane and 2-propanol: Confirmation of structure II hydrate formation. Ind. Eng. Chem. Res. 2004, 43, 4964-4966. [CrossRef]

59. Palhavanzadeh, H.; Pourranjbar, M.; Mahani, A.A.Z.; Mohammadi, A.H. Hydrate Phase Equilibria of Methane + Mixed (TBAB + THF) in the Presence and Absence of $\mathrm{NaCl}$ and/or $\mathrm{MgCl} 2$ Aquaous Solutions. J. Chem. Eng. Data 2019, 65, 217-221. [CrossRef]

60. Sangwai, J.S.; Oellrich, L. Phase equilibrium of semiclathrate hydrates of methane in aqueous solutions of tetra-n-butyl ammonium bromide (TBAB) and TBAB-NaCl. Fluid Phase Equilibria 2014, 367, 95-102. [CrossRef]

61. Veluswanry, H.P.; Kumar, A.; Kumar, R.; Linga, P. Investigation of the kinetics of mixed methane hydrate formation kinetics in saline and seawater. Appl. Energy 2019, 253, 11315. 
62. Maeda, N. Nucleation curves of methane hydrate from constant cooling ramps methods. Fuel 2018, 223, $286-293$. [CrossRef]

63. Shagapov, V.S.; Khasanov, M.K.; Musakaev, N.G.; Duong, N.H. Theoretical research of the gas hydrate deposits development using the injection of carbon dioxide. Int. J. Heat Mass Transf. 2017, 107, 347-357. [CrossRef]

64. Gambelli, A.M.; Castellani, B.; Nicolini, A.; Rossi, F. Experimental study on natural gas hydrate exploitation: Optimization of methane recovery, carbon dioxide storage and deposit structure preservation. J. Pet. Sci. Eng. 2019, 177, 594-601. [CrossRef]

65. Du, J.; Wang, X.; Liu, H.; Guo, P.; Wang, Z.; Fan, S. Experiments and prediction of phase equilibrium conditions for methane hydrate formation in the $\mathrm{NaCl}, \mathrm{CaCl}_{2}, \mathrm{MgCl}_{2}$ electrolyte solutions. Fluid Phase Equilibria 2019, 479, 1-8. [CrossRef]

66. Mohammadi, A.H.; Azfal, W.; Richon, D. Gas hydrates of methane, ethane, propane, and carbon dioxide in the presence of single $\mathrm{NaCl}, \mathrm{KCl}$, and $\mathrm{CaCl}_{2}$ aqueous solutions: Experimental measurement and predictions of dissociation conditions. J. Chem. Thermodyn. 2008, 40, 1693-1697. [CrossRef]

67. Sun, S.C.; Kong, Y.Y.; Zhang, Y.; Liu, C.L. Phase equilibrium of methane hydrate in silica sand containing chloride salt solution. J. Chem. Thermodyn. 2015, 90, 116-121. [CrossRef]

68. Shicai, S.; Yong, Z.; Changling, L.; Yufeng, L. Preliminary study on measurement technology for hydrate phase equilibrium. Fluid Phase Equilibria 2015, 403, 60-69. [CrossRef]

69. Sun, S.C.; Liu, C.L.; Ye, Y.G. Phase equilibrium condition of marine carbon dioxide hydrate. J. Chem. Thermodyn. 2013, 57, 256-260. [CrossRef]

Publisher's Note: MDPI stays neutral with regard to jurisdictional claims in published maps and institutional affiliations. 